\title{
Research Square \\ The Changing Extreme Values of Summer Relative Humidity in the Tarim Basin in Northwestern China
}

Da Nian ( $\square$ danian@pku.edu.cn)

Peking University https://orcid.org/0000-0002-2320-5223

\section{Marianna Linz}

Harvard University Division of Engineering and Applied Sciences: Harvard University John A Paulson School of Engineering and Applied Sciences

\section{Todd A. Mooring}

Harvard University

\section{Zuntao Fu}

Peking University

\section{Research Article}

Keywords: Relative humidity , Extreme wet, Quantile regression , Regional 29 meteorological anomaly patterns, Tarim Basin , Asia

Posted Date: May 10th, 2021

DOl: https://doi.org/10.21203/rs.3.rs-221433/v1

License: (c) (i) This work is licensed under a Creative Commons Attribution 4.0 International License. Read Full License

Version of Record: A version of this preprint was published at Climate Dynamics on January 21st, 2022. See the published version at https://doi.org/10.1007/s00382-021-06110-2. 


\title{
The changing extreme values of summer relative humidity in the Tarim Basin in Northwestern China
}

\author{
Da Nian - Marianna Linz . \\ 4 Todd A. Mooring - Zuntao Fu
}

6 Received: date / Accepted: date

\begin{abstract}
Relative Humidity $(R H)$ in the arid region of the Tarim Basin is crucial for many reasons. The Tarim Basin has experienced a tendency to become wetter in recent decades, and the $R H$ here also shows an increase over the past decade. However, there has been little examination of these $R H$ changes and especially the changes to the extremes. This study investigates the changes in extreme values and the probability distribution function (PDF) of summer $R H$ using quantile regression during 2006-2018 to understand the possible reasons for the increase in the summer $R H$ anomaly. We find that extremely high values of $R H$ show a consistent significant increase, while extremely low values have no regionally consistent tendency. The overall average value of $R H$ in the Tarim Basin becomes higher, driven by the upper half of the PDF. To explore the physical mechanism for these changes, we examine the corresponding regional meteorological anomaly patterns. The patterns indicate that the anomalous southwesterly airflow at $500 \mathrm{hPa}$ brings ample moisture into the basin and the ground in the middle of the basin significantly cools down when an extreme wet event occurs, promoting the occurrence of the extreme high $R H$. In this process, the contributions of water vapor transport and temperature are of equal significance though with different relative timing. These corresponding regional meteorological patterns occur more of-
\end{abstract}

National Natural Science Foundation of China (Nos. 41675049), Scholarship from China Scholarship Council (No. 201906010222).

Da Nian - Zuntao Fu

Lab for Climate and Ocean-Atmosphere Studies, Dept. of Atmospheric and Oceanic Sciences, School of Physics, Peking University, Beijing, 100871, China

E-mail: danian@pku.edu.cn

Marianna Linz

Harvard University, Earth and Planetary Sciences and School of Engineering and Applied Sciences, Cambridge, MA, 02138, United States

Todd A. Mooring

Harvard University, Earth and Planetary Sciences, Cambridge, MA, 02138, United States 
ten in the most recent decade, which coincides with the recent increase in $R H$ extremes in this region.

Keywords Relative humidity · Extreme wet - Quantile regression · Regional meteorological anomaly patterns · Tarim Basin · Asia

\section{Introduction}

Relative humidity $(R H)$, describing the distribution of water vapor in the atmosphere is of great importance for multiple fields. The Tarim Basin is the major source of dust aerosols affecting East Asian countries, and its $R H$ is closely associated with the formation of sandstorms and sand transmission (Mao et al, 2011; Li et al, 2019a; Yang et al, 2019). $R H$ directly affects the formation of dew, which is the most important water source for plants and animals' survival in the desert (Chen et al, 2020; Gong et al, 2019; Gerson et al, 2014 ). The changes of $R H$ are associated with the response of the ecological system in desert areas and water cycle to global warming (Held and Shell, 2012; Wright et al, 2010). Understanding changes in $R H$ can also provide a deeper understanding of changes in extreme events in this area (Tao et al, 2014; Sun et al, 2014; Zhang et al, 2012).

In the past decade, some researchers have shown that $R H$ over land should have a downward trend with global warming, since the more rapidly increasing temperature over land than the ocean leads to a faster increase in saturated vapor pressure with global warming, while vapor pressure over land cannot increase as rapidly (Sherwood and Fu, 2014; Collins et al, 2013; Simmons et al, 2010; Byrne and O'Gorman, 2016, 2018). This trend will lead to a drier climate in the future (Fu and Feng, 2014). However, in contrast to the overall situation over the continents, an upward variation of $R H$ in the South Xinjiang, including the Tarim Basin region, has been observed in recent decades (Chen et al, 2020). Some more observations indicate that in Northwest China, a large region including the Tarim Basin, the precipitation has increased and the climate has become wetter in recent decades (Shi et al, 2007; Han et al, 2019; Peng and Zhou, 2017; Wang et al, 2017; Chen et al, 2015; Li et al, 2016). Wetness over the Tarim Basin has shown a decadal change, i.e., specifically an increase in recent decades (Tao et al, 2014, 2016). This decadal variability suggests that large-scale theoretical analysis over land cannot simply be used to understand changes in regional-scale $R H$. So what causes the increase of $R H$ in recent decade? Water transport in some form must be part of the story in such an arid region, but this has not been explored in detail.

To better understand $R H$ changes with global warming, the local conditions must be considered. Analyzing the probability distribution function (PDF) of $R H$ locally provides a good perspective for interpreting the changes in $R H$ distributions more broadly. This study focuses on summer $R H$ over the Tarim Basin, since the majority of the precipitation falls in summertime (Huang et al, 2015), and the increase in wetness is mainly concentrated in summer (Li et al, 2016; Peng and Zhou, 2017). The change in the mean of the 
time series has a close connection with its PDF and extreme values (Huybers et al, 2014; McKinnon et al, 2016). For example, in some areas, the increase in mean temperature is mainly manifested as the effect of either a decrease in extremely low values or an increase in extremely high values (Franzke, 2013, 2015). This indicates that understanding changes in summer $R H$ extremes can also help to understand the mean $R H$ change and to explore the associated physical mechanism. However, to our knowledge, no studies have focused on the full PDF of $R H$ over the Tarim Basin. The changes to the PDF and particularly to the extreme values of summer $R H$ are the subject of this study.

In this study, we analyze daily summer $R H$ data over the Tarim Basin in order to gain a more complete picture of changes in summer $R H$. We focus on the most recent decade and explore the mechanisms of changes in $R H$ and the $R H$ probability distribution function. Existing studies generally agree about the remarkable increase in summer precipitation in this region, but there is no consensus regarding changes in the $R H$ distribution and physical reasons for the changes. Is this an intensification of the hydrological cycle or a change in the regional weather patterns? We study the changes in $R H$ extreme events and the regional anomalous meteorological patterns corresponding to the extreme events to provide a way to better understand the physical mechanisms.

This paper is organized as follows: Section 2 describes the data used in this study. In section 3 , we examine the decadal change of $R H$. In section 4 we present the statistical examination of recent changes in $R H$, including analysis of extremes and probability distribution function changes. We examine the corresponding regional anomalous meteorological patterns in section 5. We then present discussion and conclusions in section 6 .

\section{Data}

In this study, observed daily mean $R H$ data from meteorological stations in the Tarim Basin area are obtained from the China Meteorological Administration (http://data.cma.cn/) for 1979 to 2018 (as shown in Fig. 1). The quality of the data has been controlled, and after removing stations that are missing data for 7 or more continuous days during the whole period (1979.1.1-2018.12.30), 19 stations remain for this analysis. Linear interpolation has been used to fill periods of missing data less than 7 days.

In addition to the observed $R H$ records, the 2-meter temperature, 2-meter dewpoint temperature (from which $R H$ can be calculated) and precipitation from the ERA5-Land hourly reanalysis dataset over 1981-2018 (Copernicus Climate Change Service (C3S), 2019; Hersbach et al, 2020) with the resolution $0.1^{\circ} \times 0.1^{\circ}$ are used. We also use 500-hPa geopotential height (Z500), $850-\mathrm{hPa}$ geopotential height $(\mathrm{Z} 850)$, and zonal $(\mathrm{u})$ and meridional $(\mathrm{v})$ wind speed on $500 \mathrm{hPa}$ and $850 \mathrm{hPa}$ from the ERA5 hourly dataset on pressure over 1981-2018 (Copernicus Climate Change Service (C3S), 2017; Hersbach et al, 2020 ), with resolution $0.25^{\circ} \times 0.25^{\circ}$. In this study, all data from the ERA5 and ERA5-Land datasets except precipitation are processed into daily data, which 
is obtained by the average value of 4 time points $(0: 00,6: 00,12: 00,18: 00)$ per day. This averaging procedure is not necessary for precipitation because daily accumulated precipitation is directly available in the ERA5-Land data set. The summer in this study is defined as June, July and August, and all anomalies are obtained by removing the seasonal cycle, similar to previous studies (Koscielny-Bunde et al, 1998): the climatological seasonal cycle is calculated as the long-time average for each day between 1981 and 2018.

\section{Increasing local tendency of summer $R H$ during the recent decade}

We first examine the summer $R H$ anomaly by calculating the mean in each year averaged over the 19 stations, shown in Fig. 2(a). From the previous studies, it is clear that $R H$ may show interannual variability (Du et al, 2012), and in our analysis we see distinct interannual and decadal variability of summer RH over the Tarim Basin (Fig. 2a). The recent decade can be easily identified as having an upward tendency (consistent with the "becoming wetter" mentioned in section 1). But we want to understand how $R H$ has changed beyond just the change in the mean.

If we understand the recent decadal-scale trend towards higher $R H$, we may be able to better understand the mechanisms causing interannual variability in $R H$. To determine the beginning of the increasing variation, the Sequential Mann-Kendall (SQMK) method (Nasri and Modarres, 2009) is used to check for the location of a change point in the summer $R H$ anomaly time series. The method is described in the Appendix. The result shows that the transition point year is around 2006 and so we chose 2006-2018 as the period of interest for this study. The spatial distribution of the linear slope in the Tarim Basin is examined in Fig. 2(b). It shows that most stations have a tendency towards higher $R H$, which matches the results in previous studies (Han et al, 2019; Peng and Zhou, 2017; Wang et al, 2017).

\section{Statistical examination of recent changes in $R H$}

4.1 Tendencies of the extreme high and extreme low $R H$ anomaly using Quantile Regression

To understand changes in extreme values of summer $R H$ anomaly during the past decade, a non-parametric technique to estimate the slope in any percentile of a distribution, quantile regression, is employed (Koenker and Bassett Jr, 1978; Cade and Noon, 2003; Gao and Franzke, 2017; Huybers et al, 2014 ). Linear slopes in quantiles from the 5 th, 50 th and 95 th percentiles of the summer $R H$ anomaly time series at station 51639 are shown as examples (Fig. 3 ). This method can effectively show the year-by-year local trend of a specific percentile value. (For the total 92 days in the summer of each year, there is 
no impact from the day-to-day ordering on the quantile slopes.) The different slopes of the 5th and the 95th percentiles imply a change in $R H$ intraseasonal variability.

A block bootstrap is used here for the estimation of significance of the sign of the linear slopes, following McKinnon et al (2016). The fitted linear slope in the data is removed first and then the residuals are resampled with replacement using a 92 day block, which is chosen based on the assumption the $R H$ is correlated within any given summer, but has negligible interannual correlation. After adding these values back to the linear trend removed in the first step, the trend is re-estimated. The process is repeated 1000 times. As in McKinnon et al (2016), the resulting distribution of bootstrap trends is used to determine whether the trend is significant, with a somewhat unusual definition of significant as when $95 \%$ of the bootstrap slopes are of the same sign as the observed trend (regardless of the magnitude of the bootstrap slopes). This method will determine whether there is a detectable non-zero linear slope in the interannual change.

The quantile regression method is applied at all 19 stations in the Tarim Basin to investigate the changes in the summer $R H$ extreme values. The extreme dry and wet days are defined when the corresponding $R H$ is lower than the 5th percentile and higher than the 95th percentile for each summer, respectively. Figure 4 shows that there is an increasing local tendency of the 95th percentile of summer $R H$ anomaly across nearly the entire Tarim Basin area (Fig. 4c) and a weaker trend that is nevertheless largely spatially coherent in the 50th percentile (Fig. 4b). (Of course this is very similar to Fig. 2a.) There is no equivalent positive tendency for the 5th percentile (Fig. 4a); the extreme dry values of $R H$ anomaly demonstrate a complex distribution of changes with few significant tendencies. In general, the high values become higher, while the low values have no uniform tendency. The average value of $R H$ in the Tarim Basin increases, which is driven by increases in the upper half of the distribution. We thus expect that the intraseasonal variance of $R H$ has also increased, and we analyze the PDF in the next section.

\subsection{Changes in the probability distribution function}

The PDF provides a more compute picture of summer $R H$ variability and its changes. In order to observe the changes of extreme values and mean values, it is necessary to study the change of the PDF over time. We divide the data of the past 13 years into two time periods (2006-2012 and 2012-2018), and then qualitatively examine the PDF in both periods. Figure 5a shows a case study (station 51639), and the PDF of 2012-2018 is wider than the PDF during the previous time period. This case study suggests an increase in the variance of $R H$ variability over time. To test whether it is the case in the entire region, the year-by-year standard deviation of $R H$ anomalies are calculated. Figure $5 \mathrm{~b}$ shows that the mean standard deviation of each year (that is, the average 
of the annual standard deviations of 19 stations) increasing in the past decade, as we expected from Figure 5a.

The PDF of summer $R H$ anomaly in the Tarim Basin is non-Gaussian with a long wet side and a short dry side. Because the changes of non-Gaussian distributions are more complicated than those of normal distributions, the changes of extreme value are not necessarily simply a shift with the mean (Huybers et al, 2014; McKinnon et al, 2016; Loikith and Neelin, 2019). Compared with the PDF in the previous period, the long tail on the wet-side of the PDF during 2012-2018 obviously moves towards the higher value, while there is little change on the dry-side (Fig. 5a). A slight shift in the distribution peaks can also be observed (Fig. 5a). Although they differ in some details, the PDFs of the other 18 stations show similar and significant movement across the two periods, which corresponds to the results of the mean change (Fig. 2) and quantile regression (Fig. 4). There is only one station where the deviation of the second period is not obvious. Combined with the analysis above, the 95th percentile of $R H$ anomaly demonstrates a consistent increasing trend in the past decade. This increase exhibits remarkable regional consistency, implying that more extreme wet events have occurred throughout this arid area over 2006-2018. In the next section, we aim to understand this extremum change.

\section{Meteorology associated with recent changes in extreme high RH}

The previous analyses demonstrate that the changes in the mean are driven by the upper part of the distribution, and there is an increase in the wet extremes of summer $R H$ over the Tarim Basin during the recent decade. We now examine the large-scale meteorological conditions associated with the increase in extremes.

To analyze the weather associated with extreme events, one useful method is to make composites of the atmospheric fields(Gao and Franzke, 2017). Since the distribution of meteorological station data is uneven, reanalysis data has great advantages for investigating the spatial pattern of climate variables.

\subsection{Comparison between ERA5 reanalysis and observed records over the} Tarim Basin

We use ERA5 reanalysis data to examine the conditions of the weather patterns when extremely high $R H$ occurs in the observations. To verify that this is providing an adequate representation of the moisture, we first compare the summer $R H$ anomalies in observations with those in ERA5 data, as shown in Figure 6. The mean value for each summer averaged over all grid boxes in the research area using ERA5 data shows similar variability to that from 19 meteorological stations, especially in the recent decade (Fig. 6a). We also compare extremely high values of summer $R H$ in ERA5 data to those in the observations, similar to the temperature analysis done by Mao et al (2010). 
We find that values of 95 th percentile $R H$ for each summer averaged over the research area using ERA5 data agree reasonably well with those averaged from 19 meteorological stations (Fig. 6b). Thus, ERA5 data shows a good coincidence with the observations not only for the mean values but also for extremely high values, and so it can provide a relatively reliable analysis for extreme wet days. This result is not surprising, because ERA5-Land assimilates near-surface temperature and humidity data (Hersbach et al, 2020).

\subsection{Dry and hot climatology of the Tarim Basin}

Before analyzing the possible causes of extreme $R H$ events, we show the climatology in the Tarim Basin region to help contextualize the mechanism for extreme events. The Tarim Basin maintains high-temperature climatology in summer (Lu et al, 2019), an extremely arid desert area where drought occurs often (Zhang et al, 2015; Wang and Qin, 2017). Water is extremely scarce in this area, with annual precipitation less than $200 \mathrm{~mm}$ (Wang and Qin, 2017). The center of the basin is the vast Taklimakan Desert, located in northwestern China. The climatological seasonal cycle's shown in Fig. 7a, showing that the $R H$ of this region in summer is relatively low (Wang and Gaffen, 2001), and the soil is relatively drier than other seasons ( $\mathrm{Su}$ et al, 2016). All these indicate that summer is a dry season. In this case, the climatological 2-m temperature of the entire basin in summer is above $300 \mathrm{~K}$ and the climatological daily accumulated precipitation for JJA is less than $0.1 \mathrm{~mm}$ (Fig. 7). Hot and dry conditions are the normal state in JJA for the Tarim Basin, corresponding to low RH. It is difficult for moisture to be transported into the desert region. The 38-year climatological mean wind in summer shows the prevailing westerlies, with weak southwesterly airflow entering the basin at $500 \mathrm{hPa}$ and leaving the west side of the basin without penetrating the center of the desert (Fig. 7). Furthermore, near the surface, the airflow from the southwest is mainly blocked by the Himalaya Mountains, as well as the Kunlun Mountains at the south edge of the basin, which is one of the reasons for the formation of this desert (Hartmann, 2015). Tianshan Mountains are also important for the formation of the climatological characteristics in this region (Baldwin and Vecchi, 2016). The climatology at $850 \mathrm{hPa}$ demonstrates a dry and hot current bypassing the Tianshan Mountains and entering the basin area from the northeast, where the Gurbantünggüt Desert is located. The mountains to the north and south of the basin inhibit the transport of humid air. We seek to understand the extremely high $R H$ condition in such an arid area.

\subsection{Regional anomalous meteorological patterns for extreme wet events}

An detailed study of the evolution of the local weather system when extreme events occur will provide a way to better understand the underlying physical mechanism, as is commonly done to study extreme events in the extratropics 
(e.g., Westby and Black, 2015; Smith and Sheridan, 2018; Loikith and Neelin, 2019; Risbey et al, 2019; Gershunov et al, 2009; Teng et al, 2013). We look at composites of regional anomalous meteorological patterns during and leading up to extreme wet events, defined as those exceeding the 95th percentile of an averaged $R H$ anomaly time series. This time series is defined during summer over 2006-2018 as an average over 4 stations along the edges of the Tarim Basin (red stars shown in Figs. 1 and 8), thus minimizing the effects of the uneven the distribution of meteorological stations. For simplicity, only day 0 (when extremes happen), day -2 and day -4 are shown (Fig. 8), but days -3 and -1 have no surprising features.

Figure 8 shows composites of anomalies in precipitation, temperature, 500 $\mathrm{hPa}$ geopotential height (Z500), $850 \mathrm{hPa}$ geopotential height (Z850) and the corresponding anomalous wind vector over the Tarim Basin for the extreme wet days (day 0), two days preceding the extreme wet days (day -2), and four days preceding the extreme wet days (day -4). Before extreme events occur, at day -4, a small amount of anomalous precipitation occurs in the oasis and mountains on the edge of the desert. Although the desert area in the center of the basin is relatively dry (Fig. 8a), the surrounding atmosphere is getting wet. At this time, temperature anomalies are weakly negative over the basin. A low pressure anomaly appears on the western side of the basin (with the weak airflow from the south at $500 \mathrm{hPa}$ ). Z850 anomalies do not change within the basin, but negative changes can be seen around the Tianshan Mountains on the southern edge of the basin (Fig. 8a). Approaching the day when the extreme event occurs, these phenomena become more pronounced. At day -2 , positive precipitation anomalies and negative temperature anomalies take place in the basin (Fig. 8b), and the temperature decreases rapidly in the area of cold anomalies, coinciding with high pressure appearing near the surface of the Tarim Basin at $850 \mathrm{hPa}$. High vapor pressure and relatively low temperature are the conditions for high $R H$. The declining temperature and increasing moisture in the area suggest a change towards high $R H$ conditions for this region.

The changes in temperature and precipitation are exacerbated at day -2 . A large-scale cyclone centered at the west of the Tarim Basin has its east half over the desert (Fig. 8b). Compared with the composites of the Z500 anomalies and wind vector anomalies at day -4, Z500 anomalies have decreased substantially as a low pressure center has developed on the west of the Tarim Basin at day -2 (Fig. 8b). In this case, the relatively humid air current enters the basin from the south with strong winds. We note how unusual this pattern is by recalling that the mean wind pattern is just westerly (Fig. $7 \mathrm{~d}$ ).

The extreme wet day composite shows positive precipitation anomalies throughout the basin (Fig. 8c). The cold temperature anomalies have developed, with not only a strong reduction, but also an extension of the area anomalies to the entire basin. These strong negative temperature anomalies also coincide with high pressure developed at $850 \mathrm{hPa}$ near the surface. At day 0 , the cyclone at $500 \mathrm{hPa}$ amplifies considerably with the center moving eastward, increasing Z500 anomalies over the west of the Tarim Basin to the 
east, implying stronger wind from the direction of the Indian Ocean entering the basin region. We note that upper-level moisture transport from the south plays an important role in causing heavy precipitation in the summer (Huang et al, 2015), and this transport has happened more with the recovery of the Indian monsoon beginning in the early 2000's (Jin and Wang, 2017; Huang et al, 2020). Although the increase in the $R H$ that we observe begins in 2006 and not the early 2000's, the strengthening of the Indian summer monsoon is conducive to more water vapor transport into the Tarim Basin. This mechanism may contribute to the increase in the value of extreme $R H$ in the past decade. These conditions work together to cause the extreme wet events.

5.4 Contribution of moisture transport and temperature for extreme wet events

Since $R H$ is controlled by both water vapor transport and temperature, we further explore their separate evolution during the development of this regional weather system for extreme wet events. The definition of $R H$ is

$$
R H=\frac{e}{e_{s}},
$$

where $e$ is vapor pressure, and $e_{s}$ is saturation vapor pressure. $e_{s}$ is a function of temperature $T$ (e.g. by the Teten formula, Xu et al (2012)). Assuming that the air pressure is constant, $e$ is a function of specific humidity $q$, which is defined as the mass of water vapor in a unit mass of moist air. For efficient decomposition, the logarithmic form is adopted:

$$
\ln R H=\ln e-\ln e_{s} .
$$

To calculate the anomaly, we use $\ln R H=\overline{\ln R H}+(\ln R H)^{\prime}, \ln e=\overline{\ln e}+(\ln e)^{\prime}$ and $\ln e_{s}=\overline{\ln e_{s}}+\left(\ln e_{s}\right)^{\prime} . \overline{\ln R H}$ is the logarithmic climatological average of $R H$, and similarly for $\overline{\ln e}$ and $\overline{\ln e_{s}}$. Then the local derivative to analyze the change of $(\ln R H)^{\prime}$ in time using Eq. (2) is calculated:

$$
\frac{\partial}{\partial t}(\ln R H)^{\prime}=\frac{\partial}{\partial t}(\ln e)^{\prime}+\left(-\frac{\partial}{\partial t}\left(\ln e_{s}\right)^{\prime}\right)
$$

Using daily data, the daily tendency term, $\frac{\partial}{\partial t}(\ln R H)^{\prime}$, represents the daily change of $R H$ anomaly. (The use of daily data avoids the influence of unwanted diurnal signals.) Using Eq. (3), daily change of $R H$ anomaly, $\frac{\partial}{\partial t}(\ln R H)^{\prime}$, (computed as a finite difference according to $\frac{\partial}{\partial t}(\ln R H(t))^{\prime}=\ln R H(t)-$ $\ln R H(t-1)$ ), can be represented as the contribution of water vapor (the first term on the right side) and temperature (the second term on the right side).

Figure 9 shows the composites of the local daily change of $(\ln R H)^{\prime},-\left(\ln e_{s}\right)^{\prime}$ and $(\ln e)^{\prime}$ for extreme wet days (day 0) and 1-4 days prior to the extreme wet days (days $-1,-2,-3$, and -4$)$. $\frac{\partial}{\partial t}(\ln R H)^{\prime}$ increases incrementally until day -1 (Fig. 9b-e), when changes in the regional anomalous meteorological patterns 
are similar between day - 1 and day 0 than between any other two days (not shown). This reveals a more rapid development of the weather system at the beginning, approaching its mature state on day -1 , then the rate of changes slows down, with the anomalies reaching their maximum size on day 0. Compared with $\frac{\partial}{\partial t}\left(\ln e_{s}\right)^{\prime}$, the contribution of $\frac{\partial}{\partial t}(\ln e)^{\prime}$ exhibits stronger growth at day -4 , providing a considerable contribution of $70 \%$ to the total growth rate and thus suggesting a fairly important role of water vapor transport in the initial development. Then the vapor pressure contribution becomes almost the same as that of $\frac{\partial}{\partial t}\left(\ln e_{s}\right)^{\prime}$ at day -3 , indicating the equal importance for water vapor transport and temperature at this time. Subsequently, the contribution of $\frac{\partial}{\partial t}\left(\ln e_{s}\right)^{\prime}$ is comparable with $\frac{\partial}{\partial t}(\ln e)^{\prime}$ at day -2 , becoming considerably more important at day -1 to day 0 and reaching $96 \%$ at day 0 . This progression shows that the impact of temperature grows gradually with the increasing contribution of daily changes in saturation vapor pressure. Evaporation after precipitation will cool the surface, and along with the increased water vapor in the air, these conditions favor the increase of $R H$. The relationship between precipitation and surface cooling over desert is complex (Knippertz et al, 2009), however, and more observation and analysis is needed over the Tarim Basin in the future.

\subsection{Frequency of the regional anomalous meteorological patterns}

In the analysis above, we identified regional anomalous meteorological patterns associated with extreme wet events in the Tarim Basin. These patterns may also lead to many wet days that do not have $R H$ as high as the 95th percentile. The increase in frequency of high $R H$ events is not guaranteed to be due to an increase in the occurrence of this pattern. The intensifying hydrological cycle could potentially explain the change without any change to the statistics of the weather patterns. To determine if the weather pattern we identified above is related to the increase in high $R H$ events, we look to see if the pattern is happening more often in later years of our time series.

To identify the specific regional anomalous meteorological patterns over the whole period, we first define the patterns for the extreme wet days (i.e., day 0) shown in Figure 8c as the featured patterns. In Figure 8, the study area is $70^{\circ} \mathrm{E}-100^{\circ} \mathrm{E}$ and $30^{\circ} \mathrm{N}-50^{\circ} \mathrm{N}$, and there is a pattern of cooling, which shows distinct differences from the climatological mean state. Anomalous structure is also visible in the Z500 and Z850 fields. For efficient comparison and identification of days with similar patterns, the Pearson correlation is checked between the featured patterns and each day of summers 1981-2018. Due to the small amount of precipitation, only temperature, Z500 and Z850 are used. Correlation significance is determined using a t-test. Days that meet the requirement of all three fields being significantly correlated (at 99\% confidence level) with their counterparts in the composite extreme wet day are considered to have the same regional anomalous meteorological patterns as the extreme wet day. (Note that similar results can be obtained by choosing a threshold value for the 
correlation coefficient, but this t-test method is less arbitrary.) The number of effective days per year is counted as the number of occurrences of the specific regional anomalous meteorological patterns (Fig. 10). There is a large amount of interannual variability in the occurrence of this pattern during the whole period, but nevertheless, the frequency of occurrences has a roughly increasing tendency in the recent decade (Fig. 10). This is in line with our conjecture. In the past $\sim 10$ years, as the 95th percentile of $R H$ has increased, the regional anomalous meteorological patterns that occur simultaneously have also appeared more frequently. Comparing Figures $6 \mathrm{a}$ and 10, we see that the increasing summer $R H$ tendency coincides with an increasing number of the regional anomalous meteorological patterns during 2006-2018, which suggests that the regional anomalous meteorological patterns are not only associated with extreme wet days, but also play an important role in maintaining the seasonal mean RH. The decadal-scale variability occurs both in the mean summer $R H$ time series and in the frequency of the regional anomalous meteorological patterns.

\section{Discussion and Conclusions}

In the past half century, the impact of global warming has greatly increased the water holding capacity of the atmosphere (Dai, 2006). Correspondingly, the atmosphere over land is drying, since the speed of water vapor transport from ocean to land cannot keep up with the speed of the increase in temperature over land (Byrne and O'Gorman, 2018). This large-scale behavior is a clear example showing that global warming can impact the interannual change of $R H$ over land. The magnitude of the internal variability within the Earth's climate system is important for understanding interannual variability and trends in $R H$. In addition, the regional behavior may in cases be quite different from the overall expectation of drying over land.

We analyzed daily summer $R H$ data over the Tarim Basin, which is an extremely arid region dominated by a large desert. Over the record at the stations in the Tarim Basin, the $R H$ has exhibited a large amount of decadalscale variability, including an upward tendency in the summertime mean of $R H$ during 2006-2018. In light of the large-scale, long term drying trend predicted, it is important to understand the internal variability that can cause regional deviations. The desert provides a relatively simple case study, and as moisture is critical in this region, it is also an important area for predicting local environmental and economic impacts.

Studies exploring why the Tarim Basin is getting wetter (whether measured by precipitation or humidity) find different results (Huang et al, 2015; Wang et al, 2017; Li et al, 2019b; Peng et al, 2020), and this disagreement implies that more work needs to be done. We provide a novel perspective on the recent increase in $R H$. We studied the changes in the PDF and extreme values of summer $R H$. The results using quantile regression show that there was an increasing trend for the 95th percentile during 2006-2018, while there is 
no consistent regional tendency for the 5th percentile. This coincides with increasing variance and PDF changes of the summer $R H$ anomalies during the most recent decade. High values become higher, while the low values do not have a consistent change. The average value of $R H$ in the Tarim Basin becomes higher, likely driven by the upper half of the PDF.

To explore why the 95th percentile is increasing, we distinguished the regional anomalous meteorological patterns that occur at the same time as extreme wet events. The corresponding regional anomalous meteorological patterns show abnormal southwesterly airflow at $500 \mathrm{hPa}$ that transports water vapor into the basin and abnormal low temperature and high pressure near the surface with local precipitation. These processes cause the water vapor pressure to increase with more atmospheric water vapor and the saturated water vapor pressure to decrease with low surface temperature, resulting in an extremely high $R H$. The contributions of water vapor pressure and temperature show equal importance to the mechanism. In the development of this regional anomalous meteorological pattern, water vapor transmission has a greater impact in the early stage, and temperature has a greater impact in the later stage.

In addition to examining the progression of the events themselves, we identify the regional anomalous meteorological patterns associated with the extreme events. We find the occurrence of the regional meteorological pattern has increased over the past decade, providing a reasonable qualitative explanation for the increase of summer $R H$ extreme wet days. This and the asymmetric changes to the distribution both suggest that dynamical changes are important for the recent change and that the changes are not simply a thermodynamically-driven intensification of the water cycle.

The Tarim Basin is a clear demonstration of large interannual variability in $R H$ that complicates the detection of any forced trend without much longer time series. The decadal-scale variability in $R H$ extremes in this specific region is not consistent with the overall expectation for drier land areas with climate change. This recent change is likely dynamical in nature, and we see an increase in variance as well as an increase in the mean. We have focused on the most recent period as an example, and more research is needed to identify the mechanisms for the inter-decadal variability in summer $R H$ in the Tarim Basin. More regional studies of the variability and tendency of $R H$ in different areas are also necessary to investigate the nuances in predictions of decreased $R H$ over land in the future.

Acknowledgements The authors acknowledge support from the National Natural Science Foundation of China (Nos. 41675049). This work is also supported in part by a scholarship from the China Scholarship Council (No. 201906010222). We thank Peter Huybers for providing the code for quantile regression. 


\title{
A Methods used to detect the starting point of the recent trend in RH
}

\author{
A.1 Sequential Mann-Kendall test
}

To identify the change point in the summer $R H$ time series, the Sequential Mann-Kendall (SQMK) test is adopted. Based on Mann-Kendall test, Sneyers (1991) introduced sequential values to help determine the approximate year of the beginning of a significant trend. This method calculates forward and backward sequences of the test statstic and enables detection of the approximate change point of a trend from the intersection point of the two sequences. The SQMK method is frequently used to identify trend start points (Yang and Tian, 2009). For more details and calculation see Nasri and Modarres (2009).

\section{A.2 Standard Normal Homogeneity test}

We also use another method, the Standard Normal Homogeneity test (SNHT), to check the change point. The result shows that the change point year is 2005 (Other results are not sensitive to this distinction; selecting 2005 as the starting year yields similar patterns and tendencies.) The SNHT was first applied in climate science by Alexandersson (1986). SNHT is a popular and effective way to detect a change point with its nonparametric variant (Salehi et al, 2020). Under the null hypothesis, the annual means of summer $R H$ are assumed independent and identically distributed and thus the series is homogeneous. Then the test can detect the year where break occurs (Kang and Yusof, 2012). The details of this method can be found in Pohlert (2020).

\section{References}

Alexandersson H (1986) A homogeneity test applied to precipitation data. Journal of Climatology 6(6):661-675, DOI https://doi.org/10.1002/joc.3370060607

Baldwin J, Vecchi G (2016) Influence of the tian shan on arid extratropical asia. Journal of Climate 29(16):5741-5762, DOI https://doi.org/10.1175/JCLI-D-15-0490.1

Bar-Yehuda Z (2020) 'plot google map'. MATLAB central file exchange, github. https: //www.mathworks . com/matlabcentral/fileexchange/27627-zoharby-plot_google_map (accessed: 2020/08/01)

Byrne MP, O'Gorman PA (2016) Understanding decreases in land relative humidity with global warming: Conceptual model and GCM simulations. Journal of Climate 29(24):9045-9061, DOI https://doi.org/10.1175/JCLI-D-16-0351.1

Byrne MP, O'Gorman PA (2018) Trends in continental temperature and humidity directly linked to ocean warming. Proceedings of the National Academy of Sciences 115(19):48634868, DOI https://doi.org/10.1073/pnas.1722312115

Cade BS, Noon BR (2003) A gentle introduction to quantile regression for ecologists Frontiers in Ecology and the Environment 1(8):412-420, DOI https://doi.org/10.1890/ 1540-9295(2003)001[0412:AGITQR]2.0.CO;2

Chen D, Liu W, Huang F, Li Q, Uchenna-Ochege F, Li L (2020) Spatial-temporal characteristics and influencing factors of relative humidity in arid region of Northwest China during 1966-2017. Journal of Arid Land 12(3):397-412, DOI https://doi.org/10.1007/ s40333-020-0098-2

Chen Y, Li Z, Fan Y, Wang H, Deng H (2015) Progress and prospects of climate change impacts on hydrology in the arid region of Northwest China. Environmental Research 139:11-19, DOI https://doi.org/10.1016/j.envres.2014.12.029

Collins M, Knutti R, Arblaster J, Dufresne JL, Fichefet T, Friedlingstein P, Gao X, Gutowski WJ, Johns T, Krinner G, et al (2013) Long-term climate change: Projections, commitments and irreversibility. Cambridge University Press 
Copernicus Climate Change Service (C3S) (2017) ERA5: Fifth generation of ECMWF atmospheric reanalyses of the global climate: ERA5 hourly data on pressure levels from 1979 to present. Copernicus Climate Change Service Climate Data Store (CDS) Reading, United ..., DOI https://doi.org/10.24381/cds.bd0915c6

Copernicus Climate Change Service (C3S) (2019) ERA5: Fifth generation of ECMWF atmospheric reanalyses of the global climate: ERA5-Land hourly data from 1981 to present. Copernicus Climate Change Service Climate Data Store (CDS) Reading, United ..., DOI https://doi.org/10.24381/cds.e2161bac

Dai A (2006) Recent climatology, variability, and trends in global surface humidity. Journal of Climate 19(15):3589-3606, DOI https://doi.org/10.1175/JCLI3816.1

Du J, Cooper F, Fueglistaler S (2012) Statistical analysis of global variations of atmospheric relative humidity as observed by airs. Journal of Geophysical Research: Atmospheres 117(D12):D12,315(1-10), DOI https://doi.org/10.1029/2012JD017550

Franzke C (2013) A novel method to test for significant trends in extreme values in serially dependent time series. Geophysical Research Letters 40(7):1391-1395, DOI https://doi. org/10.1002/grl.50301

Franzke CL (2015) Local trend disparities of european minimum and maximum temperature extremes. Geophysical Research Letters 42(15):6479-6484, DOI https://doi.org/10.1002/ 2015GL065011

Fu Q, Feng S (2014) Responses of terrestrial aridity to global warming. Journal of Geophysical Research: Atmospheres 119(13):7863-7875, DOI https://doi.org/10.1002/ 2014JD021608

Gao M, Franzke CL (2017) Quantile regression-based spatiotemporal analysis of extreme temperature change in China. Journal of Climate 30(24):9897-9914, DOI https://doi. org/10.1175/JCLI-D-17-0356.1

Gershunov A, Cayan DR, Iacobellis SF (2009) The great 2006 heat wave over california and nevada: signal of an increasing trend. Journal of Climate 22(23):6181-6203, DOI https://doi.org/10.1175/2009JCLI2465.1

Gerson AR, Smith EK, Smit B, McKechnie AE, Wolf BO (2014) The impact of humidity on evaporative cooling in small desert birds exposed to high air temperatures. Physiological and Biochemical Zoology 87(6):782-795, DOI https://doi.org/10.1086/678956

Gong XW, Lü GH, He XM, Sarkar B, Yang XD (2019) High air humidity causes atmospheric water absorption via assimilating branches in the deep-rooted tree haloxylon ammodendron in an arid desert region of Northwest China. Frontiers in Plant Science 10:573, DOI https://doi.org/10.3389/fpls.2019.00573

Han J, Du H, Wu Z, He HS (2019) Changes in extreme precipitation over dry and wet regions of China during 1961-2014. Journal of Geophysical Research: Atmospheres 124(11):58475859, DOI https://doi.org/10.1029/2018JD029974

Hartmann DL (2015) Global Physical Climatology, vol 103. Newnes

Held IM, Shell KM (2012) Using relative humidity as a state variable in climate feedback analysis. Journal of Climate 25(8):2578-2582, DOI https://doi.org/10.1175/ JCLI-D-11-00721.1

Hersbach H, et al (2020) The ERA5 global reanalysis. Quarterly Journal of the Royal Meteorological Society 146(730):1999-2049, DOI https://doi.org/10.1002/qj.3803

Huang W, Feng S, Chen J, Chen F (2015) Physical mechanisms of summer precipitation variations in the Tarim Basin in Northwestern China. Journal of Climate 28(9):3579-3591, DOI https://doi.org/10.1175/JCLI-D-14-00395.1

Huang X, Zhou T, Turner A, Dai A, Chen X, Clark R, Jiang J, Man W, Murphy J, Rostron J, et al (2020) The recent decline and recovery of Indian summer monsoon rainfall: Relative roles of external forcing and internal variability. Journal of Climate 33(12):5035-5060, DOI https://doi.org/10.1175/JCLI-D-19-0833.1

Huybers P, McKinnon KA, Rhines A, Tingley M (2014) US daily temperatures: The meaning of extremes in the context of nonnormality. Journal of Climate 27(19):7368-7384, DOI https://doi.org/10.1175/JCLI-D-14-00216.1

Jin Q, Wang C (2017) A revival of Indian summer monsoon rainfall since 2002. Nature Climate Change 7(8):587-594, DOI https://doi.org/10.1038/nclimate3348

Kang HM, Yusof F (2012) Homogeneity tests on daily rainfall series. Int J Contemp Math Sciences 7(1):9-22 
Knippertz P, Trentmann J, Seifert A (2009) High-resolution simulations of convective cold pools over the northwestern Sahara. Journal of Geophysical Research: Atmospheres 114(D8), DOI https://doi.org/10.1029/2008JD011271

Koenker R, Bassett Jr G (1978) Regression quantiles. Econometrica: Journal of the Econometric Society pp 33-50, DOI https://doi.org/10.2307/1913643

Koscielny-Bunde E, Bunde A, Havlin S, Roman HE, Goldreich Y, Schellnhuber HJ (1998) Indication of a universal persistence law governing atmospheric variability. Physical Review Letters 81(3):729, DOI https://doi.org/10.1103/PhysRevLett.81.729

Li B, Chen Y, Chen Z, Xiong H, Lian L (2016) Why does precipitation in Northwest China show a significant increasing trend from 1960 to 2010? Atmospheric Research 167:275284, DOI https://doi.org/10.1016/j.atmosres.2015.08.017

Li Q, Liu Y, Nakatsuka T, Fang K, Song H, Liu R, Sun C, Li G, Wang K (2019a) East Asian Summer Monsoon moisture sustains summer relative humidity in the southwestern Gobi Desert, China: evidence from $\delta 18$ o of tree rings. Climate Dynamics 52(11):6321-6337, DOI https://doi.org/10.1007/s00382-018-4515-6

Li X, You Q, Ren G, Wang S, Zhang Y, Yang J, Zheng G (2019b) Concurrent droughts and hot extremes in Northwest China from 1961 to 2017. International Journal of Climatology 39(4):2186-2196, DOI https://doi.org/10.1002/joc.5944

Loikith PC, Neelin JD (2019) Non-gaussian cold-side temperature distribution tails and associated synoptic meteorology. Journal of Climate 32(23):8399-8414, DOI https://doi. org/10.1175/JCLI-D-19-0344.1

Lu C, Huang G, Wang X (2019) Projected changes in temperature, precipitation, and their extremes over China through the RegCM. Climate Dynamics 53(9-10):5859-5880, DOI https://doi.org/10.1007/s00382-019-04899-7

Mao J, Shi X, Ma L, Kaiser DP, Li Q, Thornton PE (2010) Assessment of reanalysis daily extreme temperatures with China's homogenized historical dataset during 19792001 using probability density functions. Journal of Climate 23(24):6605-6623, DOI https://doi.org/10.1175/2010JCLI3581.1

Mao R, Ho CH, Shao Y, Gong DY, Kim J (2011) Influence of Arctic Oscillation on dust activity over northeast Asia. Atmospheric Environment 45(2):326-337, DOI https://doi. org/10.1016/j.atmosenv.2010.10.020

McKinnon KA, Rhines A, Tingley MP, Huybers P (2016) The changing shape of Northern Hemisphere summer temperature distributions. Journal of Geophysical Research: Atmospheres 121(15):8849-8868, DOI https://doi.org/10.1002/2016JD025292

Nasri M, Modarres R (2009) Dry spell trend analysis of Isfahan Province, Iran. International Journal of Climatology: A Journal of the Royal Meteorological Society 29(10):1430-1438, DOI https://doi.org/10.1002/joc.1805

Pawlowicz R (2020) M_Map: A mapping package for MATLAB, version $1.4 \mathrm{~m}$ (computer software). www. eoas.ubc.ca/ rich/map.html (accessed: 2020/08/01)

Peng D, Zhou T (2017) Why was the arid and semiarid northwest China getting wetter in the recent decades? Journal of Geophysical Research: Atmospheres 122(17):9060-9075, DOI https://doi.org/10.1002/2016JD026424

Peng D, Zhou T, Zhang L (2020) Moisture sources associated with precipitation during dry and wet seasons over Central Asia. Journal of Climate pp 1-47, DOI https://doi.org/10. 1175/JCLI-D-20-0029.1

Pohlert T (2020) Non-parametric trend tests and change-point detection. CC BY-ND 4 , URL https://cran.r-project.org/web/packages/trend/trend.pdf

Risbey JS, Monselesan DP, O'Kane TJ, Tozer CR, Pook MJ, Hayman PT (2019) Synoptic and large-scale determinants of extreme austral frost events. Journal of Applied Meteorology and Climatology 58(5):1103-1124, DOI https://doi.org/10.1175/JAMC-D-18-0141.1

Salehi S, Dehghani M, Mortazavi SM, Singh VP (2020) Trend analysis and change point detection of seasonal and annual precipitation in Iran. International Journal of Climatology 40(1):308-323, DOI https://doi.org/10.1002/joc.6211

Sherwood S, Fu Q (2014) A drier future? Science 343(6172):737-739, DOI https://doi.org/ $10.1126 /$ science. 1247620

Shi Y, Shen Y, Kang E, Li D, Ding Y, Zhang G, Hu R (2007) Recent and future climate change in Northwest China. Climatic Change 80(3-4):379-393, DOI https://doi.org/10. 1007/s10584-006-9121-7 
Simmons A, Willett K, Jones P, Thorne P, Dee D (2010) Low-frequency variations in surface atmospheric humidity, temperature, and precipitation: Inferences from reanalyses and monthly gridded observational data sets. Journal of Geophysical Research: Atmospheres 115(D1):D01,110(1-21), DOI https://doi.org/10.1029/2009JD012442

Smith ET, Sheridan SC (2018) The characteristics of extreme cold events and cold air outbreaks in the eastern United States. International Journal of Climatology 38:807-820, DOI https://doi.org/10.1002/joc.5408

Sneyers R (1991) On the statistical analysis of series of observations. 143, Geneva: Secretariat of the World Meteorological Organization

Su B, Wang A, Wang G, Wang Y, Jiang T (2016) Spatiotemporal variations of soil moisture in the Tarim River Basin, China. International Journal of Applied Earth Observation and Geoinformation 48:122-130, DOI https://doi.org/10.1016/j.jag.2015.06.012

Sun G, Chen Y, Li W, Pan C, Li J, Yang Y (2014) Intra-annual distribution and decadal change in extreme hydrological events in Xinjiang, Northwestern China. Natural Hazards 70(1):119-133, DOI https://doi.org/10.1007/s11069-012-0242-1

Tao H, Borth H, Fraedrich K, Su B, Zhu X (2014) Drought and wetness variability in the Tarim River Basin and connection to large-scale atmospheric circulation. International Journal of Climatology 34(8):2678-2684, DOI https://doi.org/10.1002/joc.3867

Tao H, Borth H, Fraedrich K, Schneidereit A, Zhu X (2016) Hydrological extremes in the Aksu-Tarim River Basin: Climatology and regime shift. Climate Dynamics 46(7-8):2029 2037, DOI https://doi.org/10.1007/s00382-015-2649-3

Teng H, Branstator G, Wang H, Meehl GA, Washington WM (2013) Probability of US heat waves affected by a subseasonal planetary wave pattern. Nature Geoscience 6(12):10561061, DOI https://doi.org/10.1038/ngeo1988

Wang JX, Gaffen DJ (2001) Late-twentieth-century climatology and trends of surface humidity and temperature in China. Journal of Climate 14(13):2833-2845, DOI https: //doi.org/10.1175/1520-0442(2001)014<2833:LTCCAT $\rangle 2.0 . C O ; 2$

Wang YJ, Qin DH (2017) Influence of climate change and human activity on water resources in arid region of Northwest China: An overview. Advances in Climate Change Research 8(4):268-278, DOI https://doi.org/10.1016/j.accre.2017.08.004

Wang Z, Li J, Lai C, Zeng Z, Zhong R, Chen X, Zhou X, Wang M (2017) Does drought in China show a significant decreasing trend from 1961 to 2009? Science of the Total Environment 579:314-324, DOI https://doi.org/10.1016/j.scitotenv.2016.11.098

Westby RM, Black RX (2015) Development of anomalous temperature regimes over the southeastern United States: Synoptic behavior and role of low-frequency modes. Weather and Forecasting 30(3):553-570, DOI https://doi.org/10.1175/WAF-D-14-00093.1

Wright JS, Sobel A, Galewsky J (2010) Diagnosis of zonal mean relative humidity changes in a warmer climate. Journal of Climate 23(17):4556-4569, DOI https://doi.org/10.1175/ 2010JCLI3488.1

Xu J, Wei Q, Peng S, YU Y (2012) Error of saturation vapor pressure calculated by different formulas and its effect on calculation of reference evapotranspiration in high latitude cold region. Procedia Engineering 28:43-48, DOI https://doi.org/10.1016/j.proeng.2012.01. 680

Yang X, Zhou C, Huo W, Yang F, Liu X, Mamtimin A (2019) A study on the effects of soil moisture, air humidity, and air temperature on wind speed threshold for dust emissions in the Taklimakan Desert. Natural Hazards 97(3):1069-1081, DOI https://doi.org/10.1007/ s11069-019-03686-1

Yang Y, Tian F (2009) Abrupt change of runoff and its major driving factors in Haihe River Catchment, China. Journal of Hydrology 374(3-4):373-383, DOI https://doi.org/ 10.1016/j.jhydrol.2009.06.040

Zhang Q, Li J, Singh VP, Bai Y (2012) SPI-based evaluation of drought events in Xinjiang, China. Natural Hazards 64(1):481-492, DOI https://doi.org/10.1007/s11069-012-0251-0

Zhang Q, Sun P, Li J, Xiao M, Singh VP (2015) Assessment of drought vulnerability of the Tarim River Basin, Xinjiang, China. Theoretical and Applied Climatology 121(1-2):337347, DOI https://doi.org/10.1007/s00704-014-1234-8 

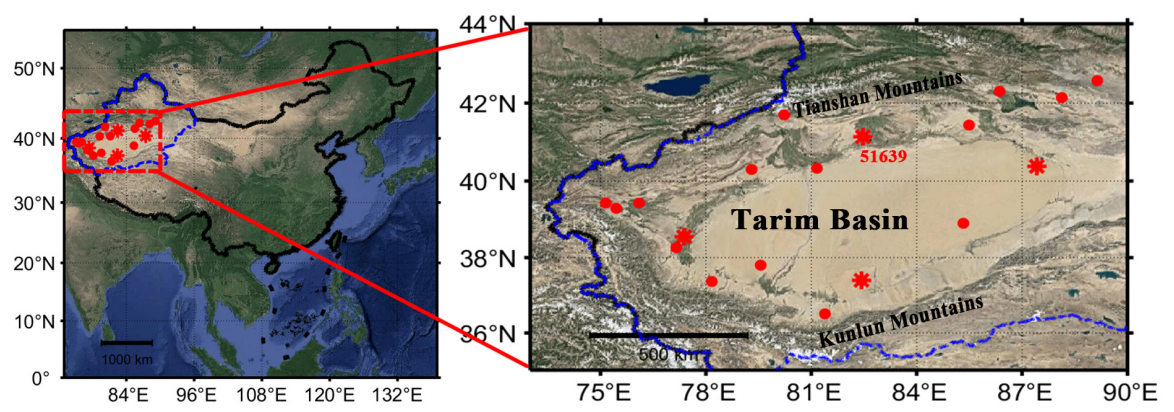

Fig. 1 Location and distribution of observation stations in the Tarim Basin. The red stars indicate the four stations located on the four edges of the desert (station 51639, shown in Fig. 3 , is an edge station at the north edge). The center of the basin is the Taklimakan Desert, with tall mountains in the north and south. The map is created from the geographical information using the Google Maps API (http://code.google.com/apis/maps/) with the M_Map mapping package ((Pawlowicz, 2020)) and Matlab code (Bar-Yehuda, 2020). 

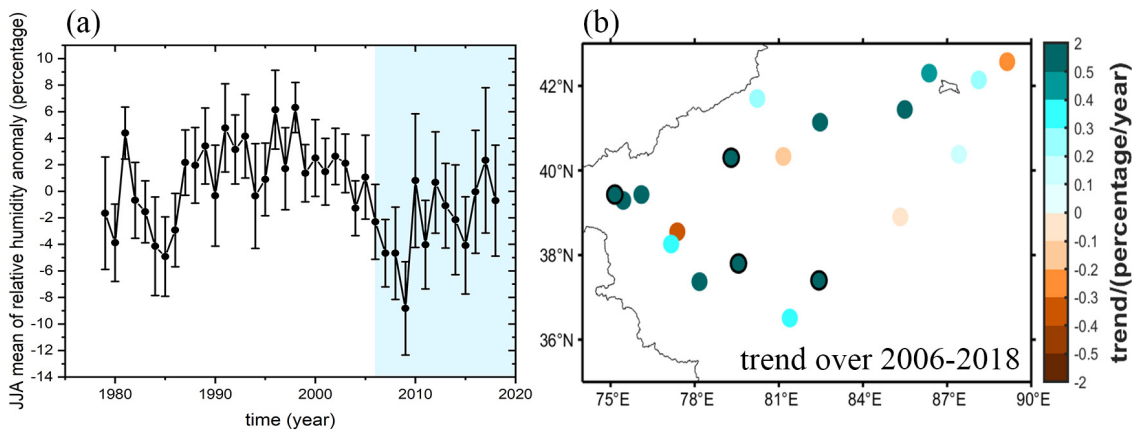

Fig. 2 (a) JJA (June, July, August) mean value of $R H$ averaged over the 19 stations for 1981-2018, the error bar shows the standard deviation of this spatial mean value; (b) the tendency of $R H$ in JJA over 2006-2018 for each station. The black circle indicates stations with a significant trend at $95 \%$ confidence based on a two-sided t-test. The blue shaded area represents the period 2006-2018. Most stations show the increasing tendency over the Tarim Basin reflected in the mean (not shown). 


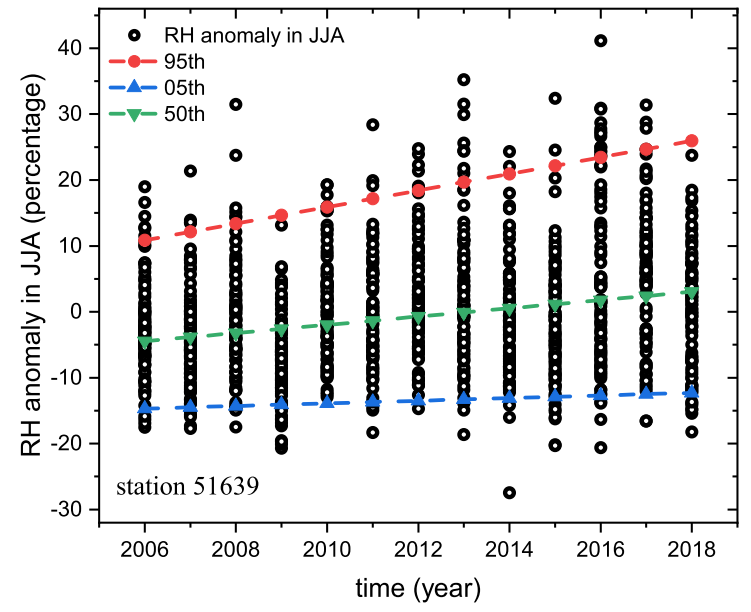

Fig. 3 Quantile regression example for $R H$ anomalies in JJA at station 51639 in the Tarim basin. Daily $R H$ anomaly data is shown as a function of year (black circles). The dashed lines are the trends in the different percentiles, with red corresponding to the 95th percentile, blue corresponding to the 5 th percentile, and green corresponding to the 50th percentile. 


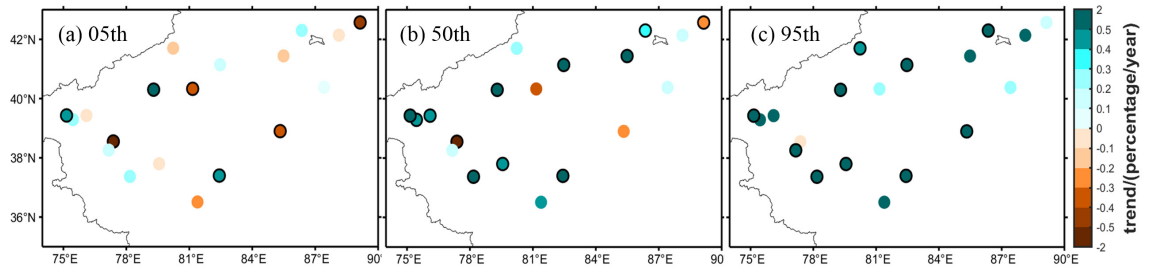

Fig. 4 Quantile regression trends of (a) 5th, (b) 50th and (c) 95th percentile of $R H$ over JJA in the Tarim Basin during 2006-2018. The black-outlined circles show stations where the trends are found to be significant based on a bootstrap analysis (see text), whereas the circles without outlining show stations with insignificant trends. The 95th percentile shows a consistent and increasing tendency during this period, while the 5th percentile does not have a consistent tendency. 

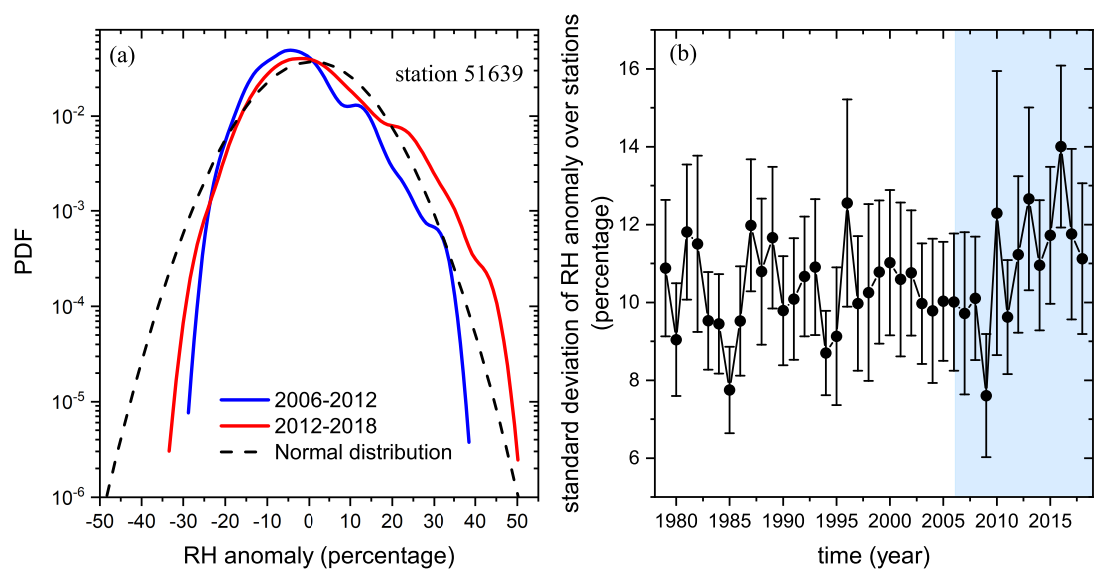

Fig. 5 (a) Probability distribution function (PDF) of $R H$ anomaly in JJA at station 51639 for two periods, where the red line is for 2012-2018, and the blue line is for 2006-2012. The dashed line is a normal distribution with the same mean and standard deviation as the JJA $R H$ anomaly PDF during 2012-2018. (b) Mean standard deviation of $R H$ anomaly each year during summertime (JJA), computed by averaging each year's standard deviations over all 19 stations. The error bar shows the standard deviation of each year's collection of 19 station standard deviations. The blue shaded area indicates the period 2006-2018, which is the period that this study focuses on. It clearly shows that the standard deviation started to increase around 2006 . 

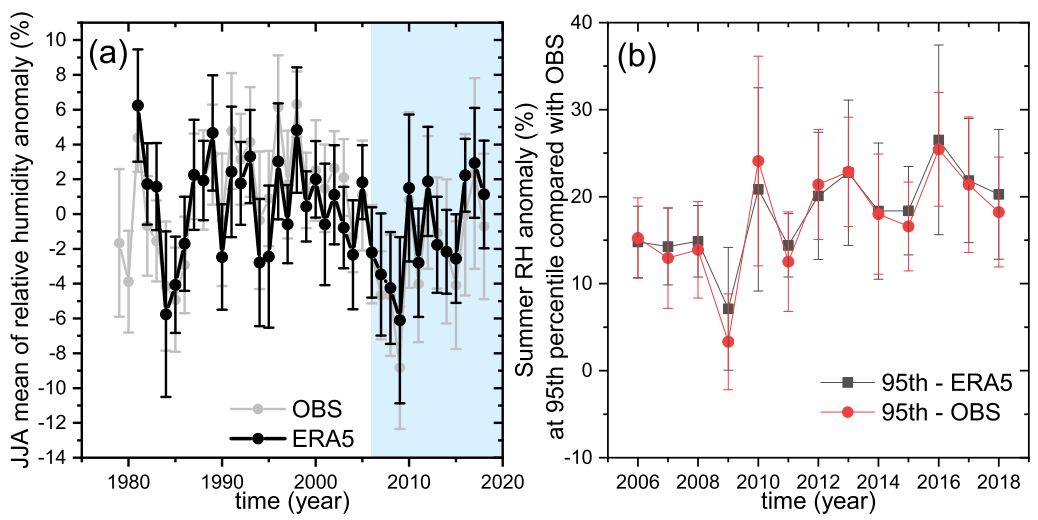

Fig. 6 (a) JJA (June, July, August) mean of $R H$ anomaly in each year averaged over the study area $\left(74^{\circ} \mathrm{E}-90^{\circ} \mathrm{E}, 35^{\circ} \mathrm{N}-43^{\circ} \mathrm{N}\right)$ using ERA5 data over 1981-2018 (black line). JJA mean of $R H$ anomaly calculated from the observations is shown as a gray line, which indicates good agreement between the two sets of data. The blue shaded area indicates the period 2006-2018. (b) The Tarim Basin-averaged 95th percentile value of JJA $R H$ anomaly for each year. The red line is calculated by averaging the observed station-level 95th percentiles over the 19 stations and the black line is calculated by averaging the ERA5 grid box-level 95th percentiles over the whole study area. There is good agreement between the observations and ERA5 data for these extremely high values of JJA $R H$ anomaly. The error bars in both panels show the (spatial) standard deviations of the individual station (OBS) or grid box (ERA5) values. 
(a)

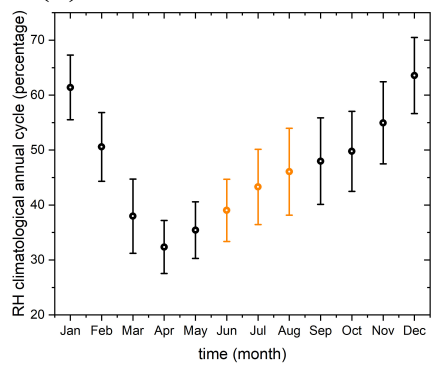

(b)

$\mathrm{T} 2 \mathrm{~m}$

(c)

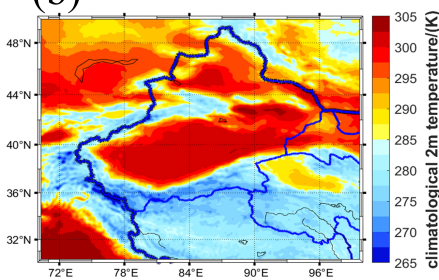

(d) Z500
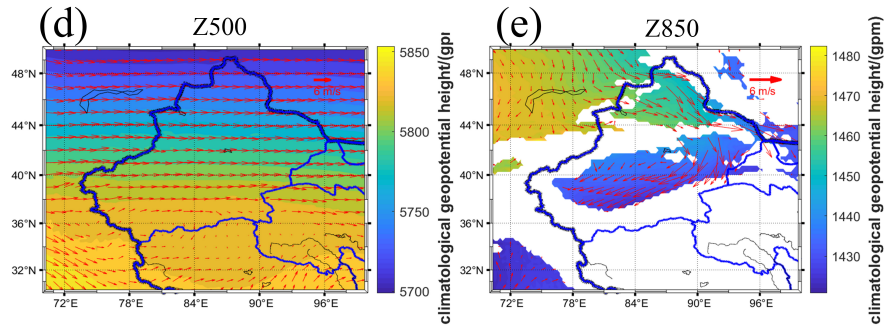

Fig. 7 (a) The climatology of $R H$ averaged over 1981-2018. The climatological mean in JJA for (b) 2-m Temperature (K), (c) precipitation (cumulative daily amount; mm), (d) 500-hPa geopotential height $(\mathrm{m})$ (Z500), (e) 850-hPa geopotential height $(\mathrm{m})$ (Z850). The red vector arrows indicate the climatological wind speed $(\mathrm{m} / \mathrm{s})$ at 500 and $850 \mathrm{hPa}$, respectively. The wind speed intensity is indicated in the upper right corners of $(\mathrm{d})$ and (e). For Z850, the area where the surface pressure is lower than $850-\mathrm{hPa}$ is set to white to avoid attempting to interpret data on underground pressure surfaces. Note that the 500 and $850 \mathrm{hPa}$ wind vectors have different scalings. Overall, these climatological fields show that the Tarim Basin maintains a dry and hot climate. 


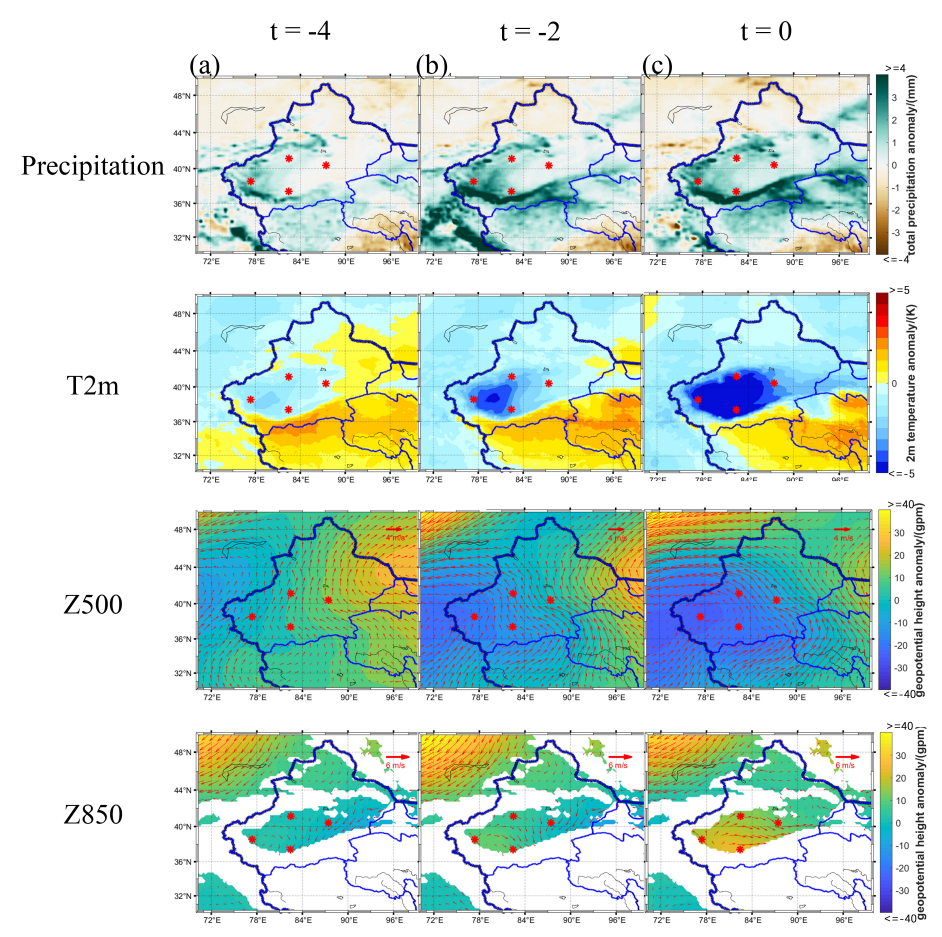

Fig. 8 Composite time-evolution maps for (a) day -4 (the first column), (b) day -2 (the second column) and (c) day 0 (the third column) for extreme wet days exceeding the 95th percentile of the distribution of an averaged $R H$ anomaly, which is computed from 4 stations $(51639,51810,51839,51765$, shown as red stars) at the edges of the Tarim Basin, during JJA (local summer). Composites are for anomalies of climate variables: total precipitation anomalies (Precipitation, $\mathrm{mm}$ ); 2-m temperature anomalies (T2m, K); 500-hPa geopotential height anomalies $(\mathrm{Z} 500, \mathrm{~m})$ and $500-\mathrm{hPa}$ wind anomalies (vectors, $\mathrm{m} / \mathrm{s}$ ); 850$\mathrm{hPa}$ geopotential height anomalies $(\mathrm{Z} 850, \mathrm{~m})$ and $850-\mathrm{hPa}$ wind anomalies $(\mathrm{m} / \mathrm{s}$; vectors). For Z850, the area where the surface pressure is lower than $850-\mathrm{hPa}$ is set to white. The wind speed intensity is indicated in the upper right corner of the relevant panels. 


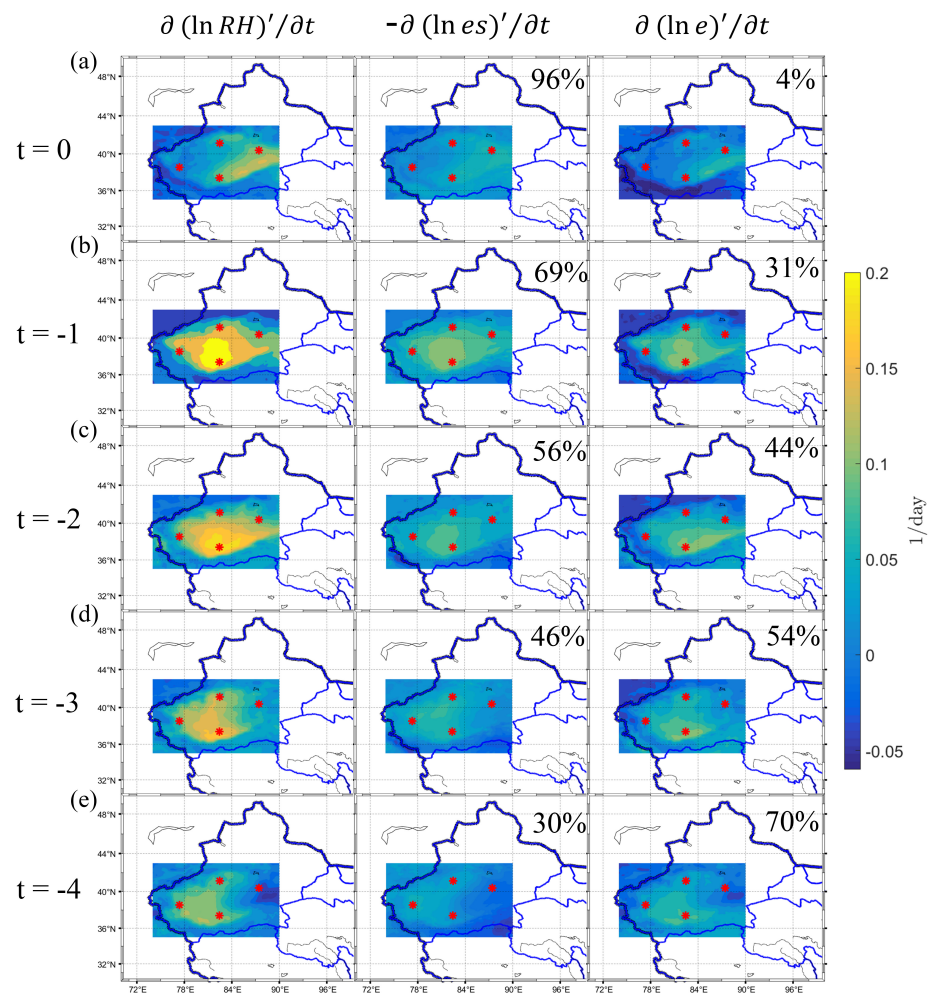

Fig. 9 Composite time-evolution maps for (a)day 0, (b)day -1, (c)day -2, (d)day -3 and (e)day -4 for the extreme $R H$ events (same definition as in Fig. 8). The study region is $74^{\circ} \mathrm{E}-$ $90^{\circ} \mathrm{E}$ and $35^{\circ} \mathrm{N}-43^{\circ} \mathrm{N}$. The three columns of composites describe the local tendency changes of $(\ln R H)^{\prime},-\left(\ln e_{s}\right)^{\prime}$ and $(\ln e)^{\prime}$, respectively. Non-dimensionalization has been applied before transforming to the log form of these climate variables. Daily data are used here and the units are 1/day for all local tendencies. These local tendencies also can be regarded as the daily change of $(\ln R H)^{\prime},-\left(\ln e_{s}\right)^{\prime}$ and $(\ln e)^{\prime}$ before the extreme wet events. The ratio of the shaded-region averages of $-\frac{\partial}{\partial t}\left(\ln e_{s}\right)^{\prime}$ and $\frac{\partial}{\partial t}(\ln R H)^{\prime}$ are shown in the upper right corner of each middle-column panel. Similarly, the ratio between $\frac{\partial}{\partial t}(\ln e)^{\prime}$ and $\frac{\partial}{\partial t}(\ln R H)^{\prime}$ shown in the upper right corner of each right-column panel. These ratios roughly show the contributions of the two components of $\frac{\partial}{\partial t}(\ln R H)^{\prime}$ each day before the extreme wet days. 


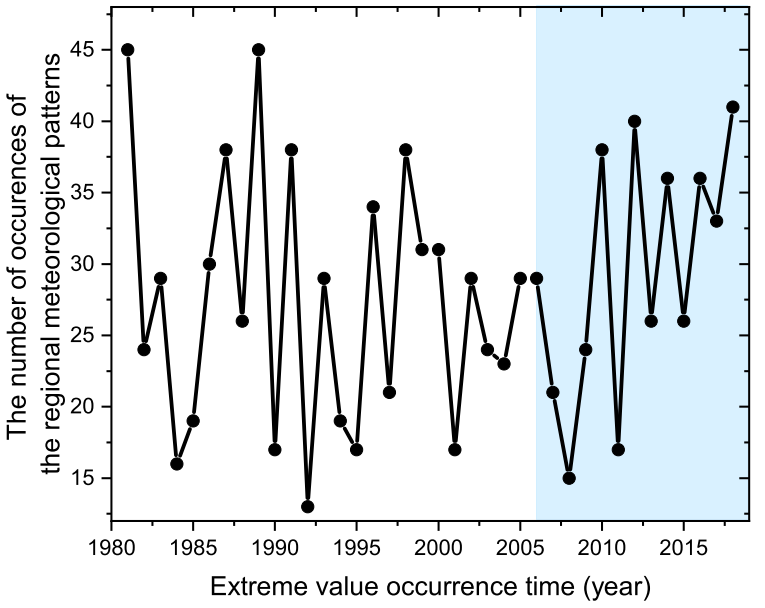

Fig. 10 Frequency of occurrence of the regional anomalous meteorological pattern corresponding to the 95th percentile extreme wet events each year from 1981 to 2018 . The blue shaded area represents the period 2006-2018. We see that during 2006-2018 the anomalous weather pattern tends to occur more frequently over time. 


\section{Figures}

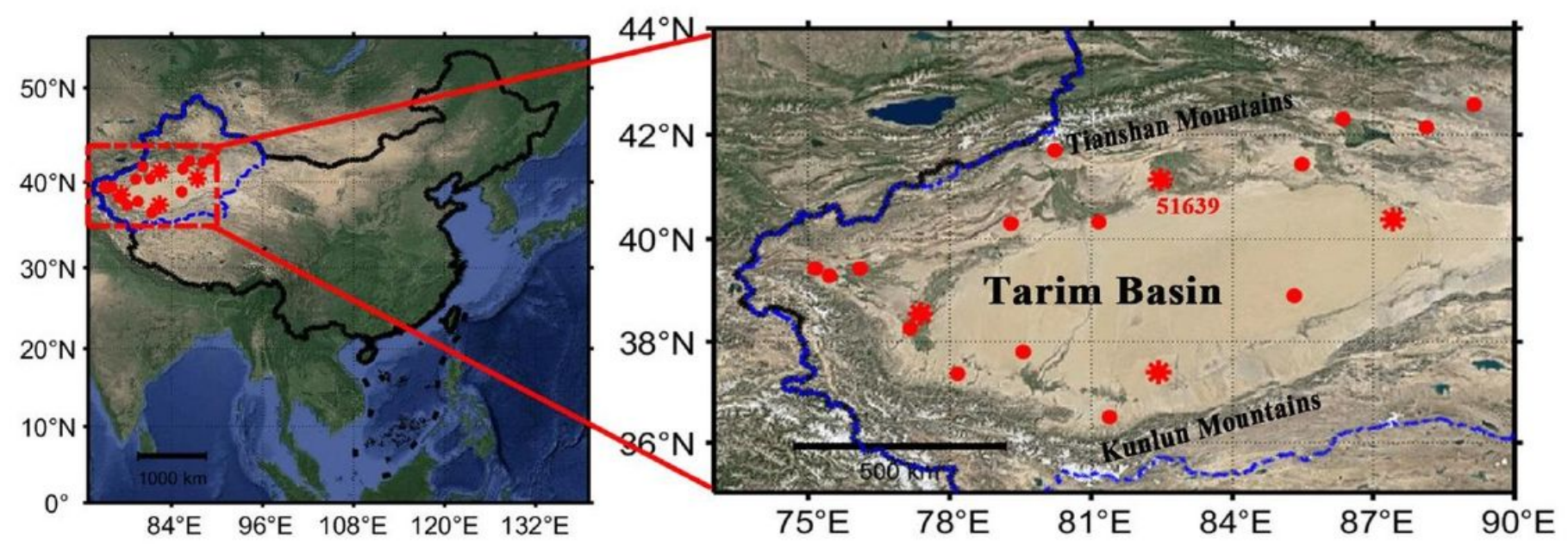

Figure 1

Please see the Manuscript PDF file for the complete figure caption Note: The designations employed and the presentation of the material on this map do not imply the expression of any opinion whatsoever on the part of Research Square concerning the legal status of any country, territory, city or area or of its authorities, or concerning the delimitation of its frontiers or boundaries. This map has been provided by the authors.
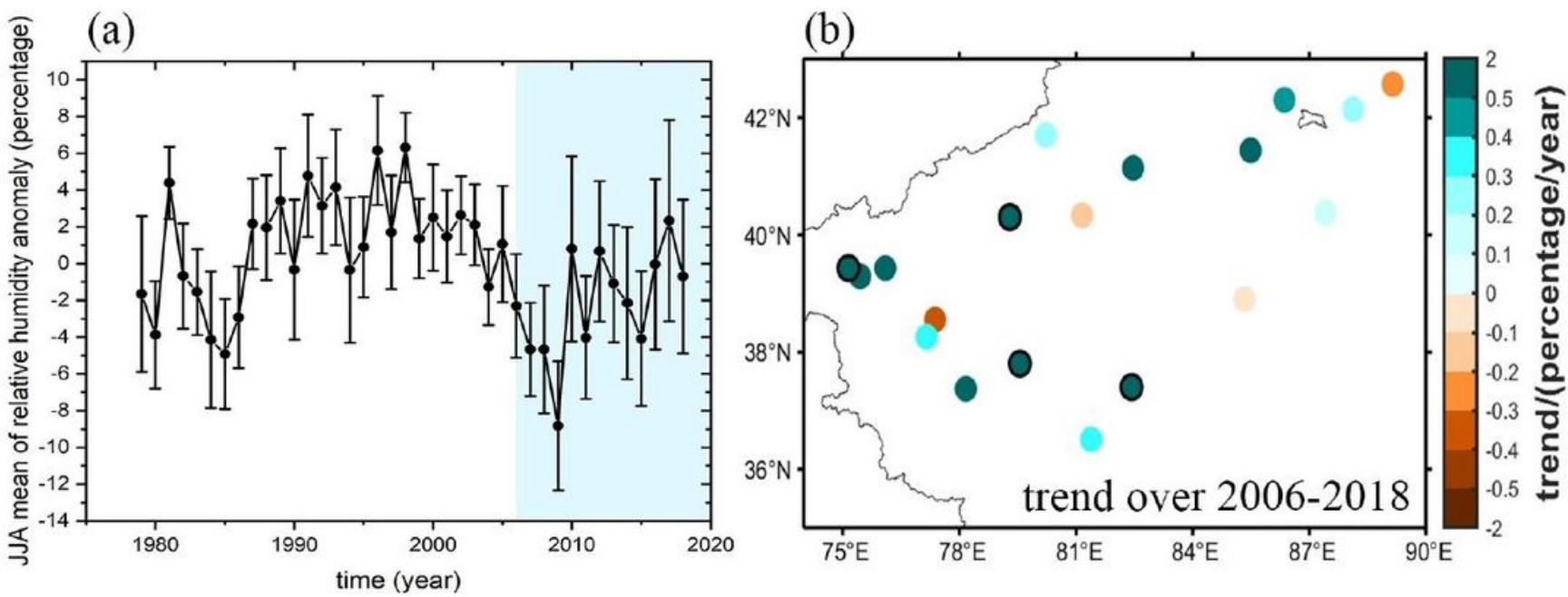

\section{Figure 2}

Please see the Manuscript PDF file for the complete figure caption Note: The designations employed and the presentation of the material on this map do not imply the expression of any opinion whatsoever on the part of Research Square concerning the legal status of any country, territory, city or area or of its 
authorities, or concerning the delimitation of its frontiers or boundaries. This map has been provided by the authors.

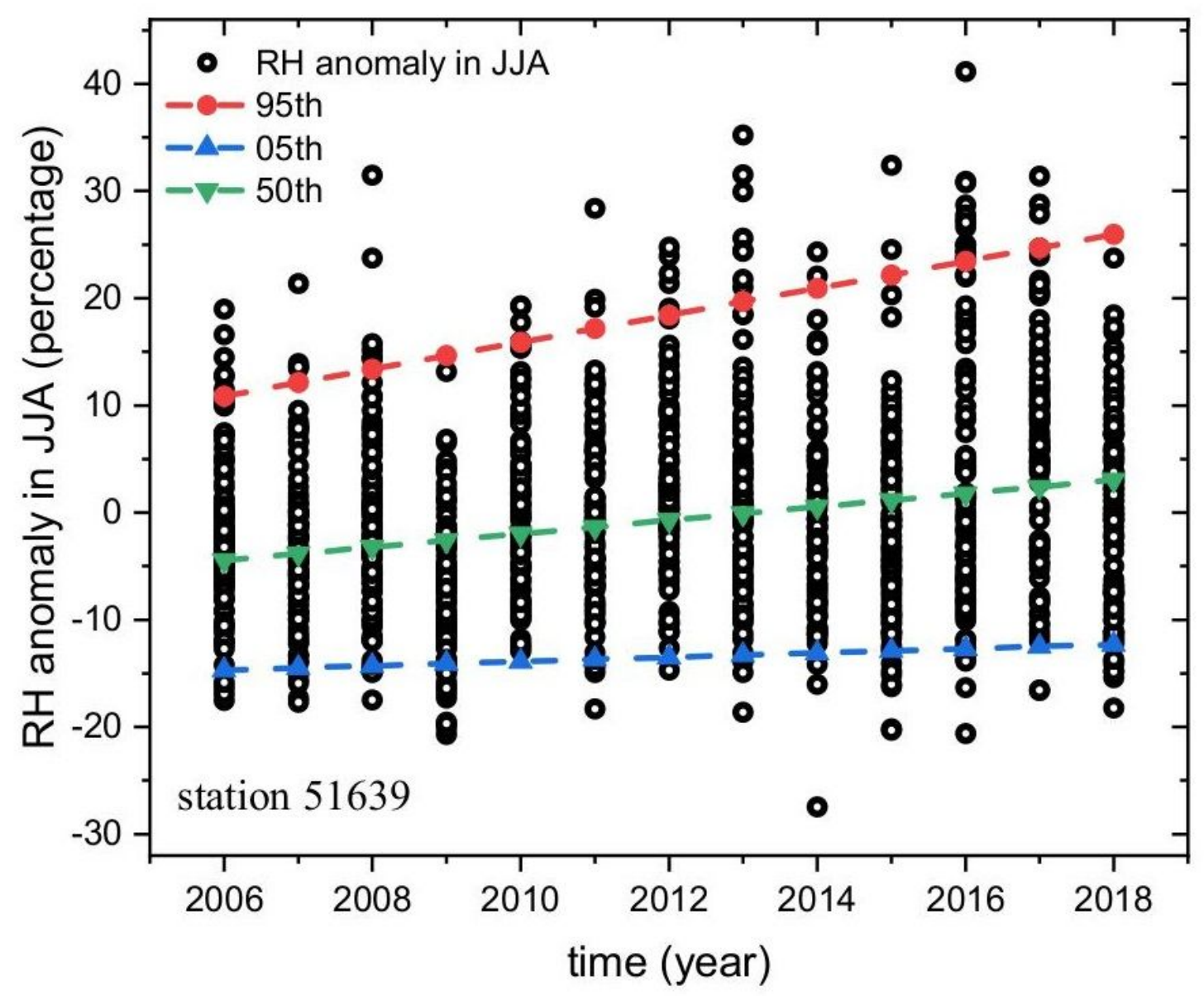

Figure 3

Please see the Manuscript PDF file for the complete figure caption

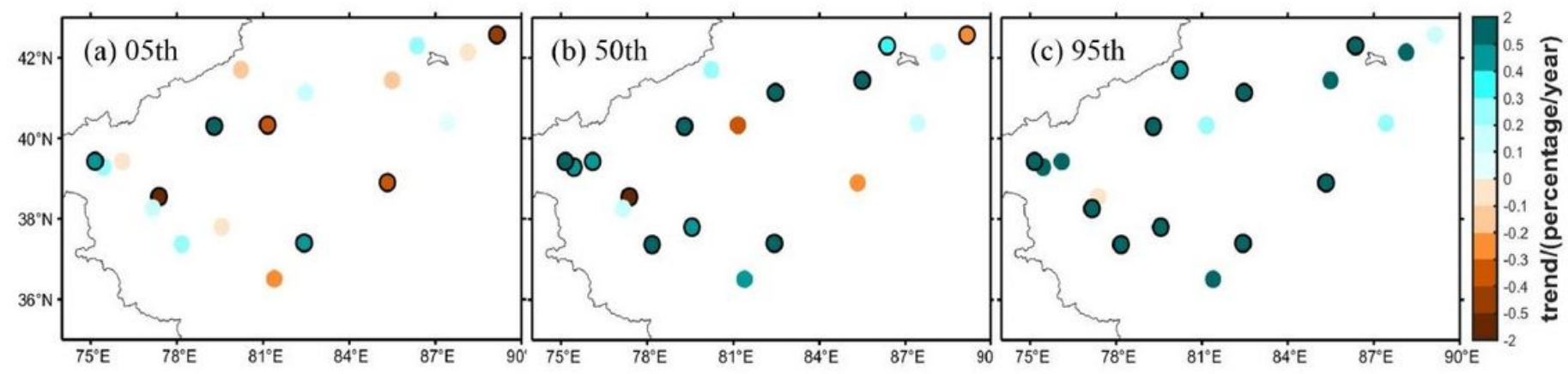

Figure 4 
Please see the Manuscript PDF file for the complete figure caption. Note: The designations employed and the presentation of the material on this map do not imply the expression of any opinion whatsoever on the part of Research Square concerning the legal status of any country, territory, city or area or of its authorities, or concerning the delimitation of its frontiers or boundaries. This map has been provided by the authors.
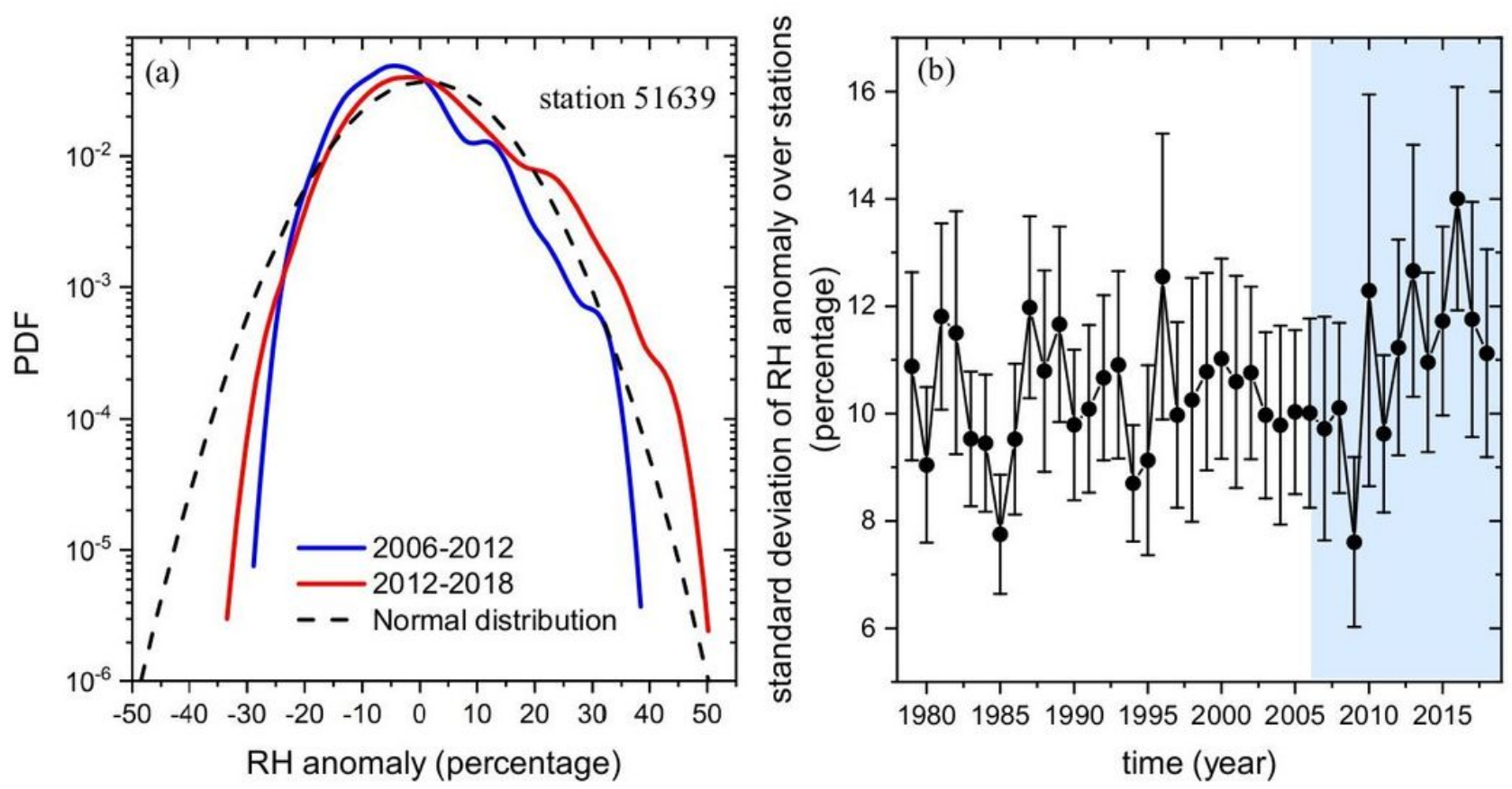

\section{Figure 5}

Please see the Manuscript PDF file for the complete figure caption
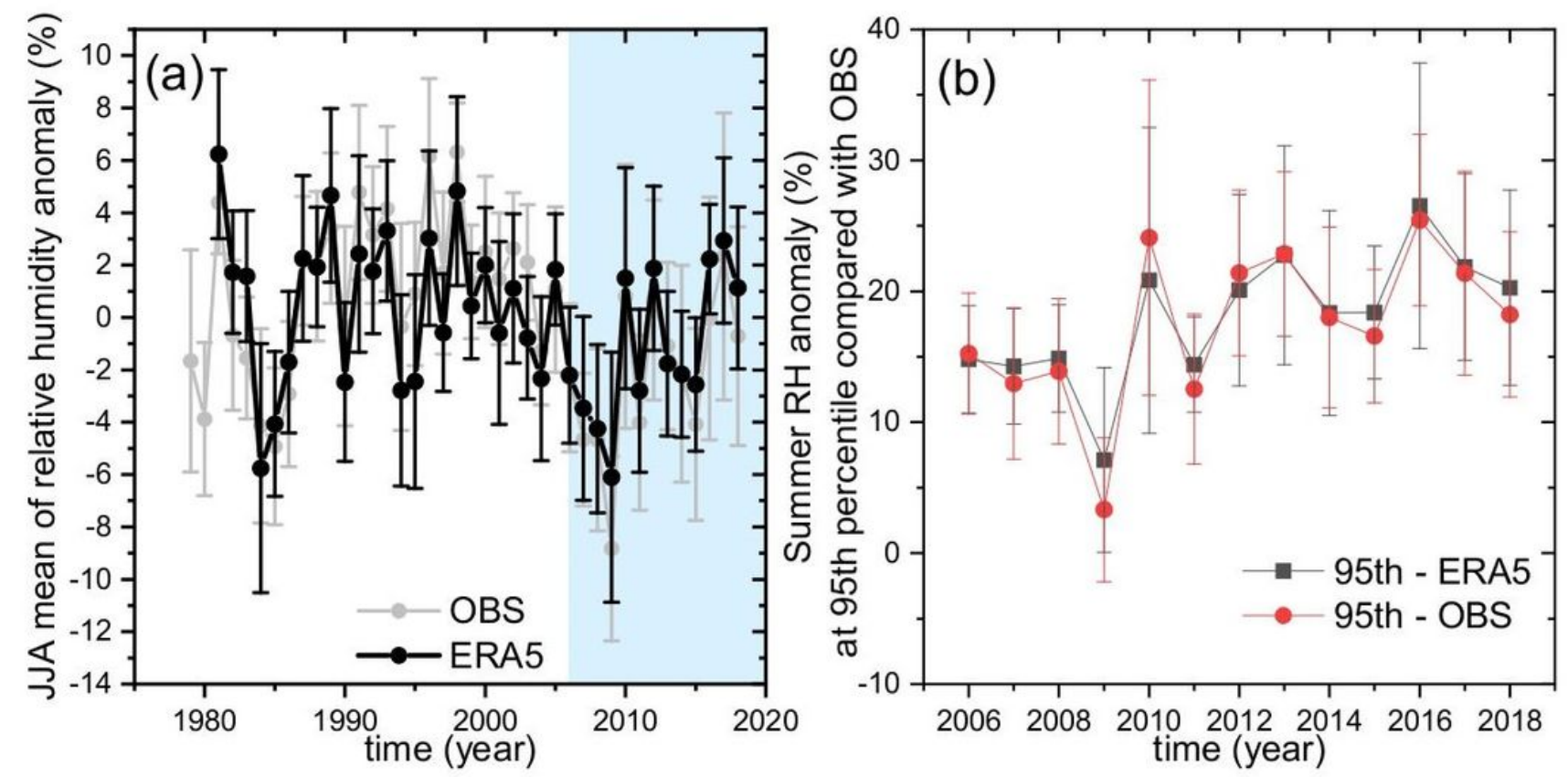

Figure 6 
Please see the Manuscript PDF file for the complete figure caption

(a)
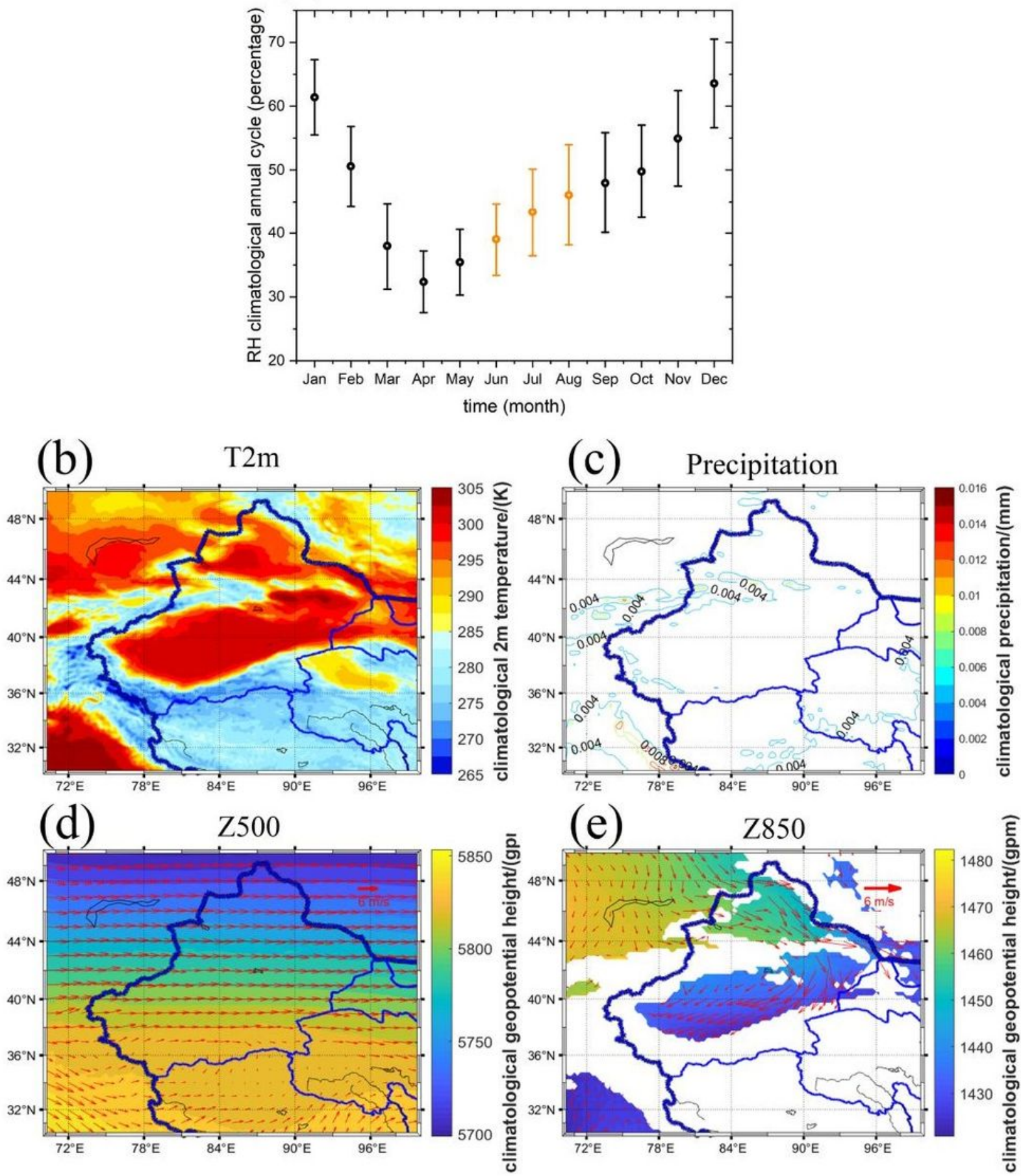

Figure 7

Please see the Manuscript PDF file for the complete figure caption Note: The designations employed and the presentation of the material on this map do not imply the expression of any opinion whatsoever on the part of Research Square concerning the legal status of any country, territory, city or area or of its authorities, or concerning the delimitation of its frontiers or boundaries. This map has been provided by the authors. 
$t=-4$

(a)

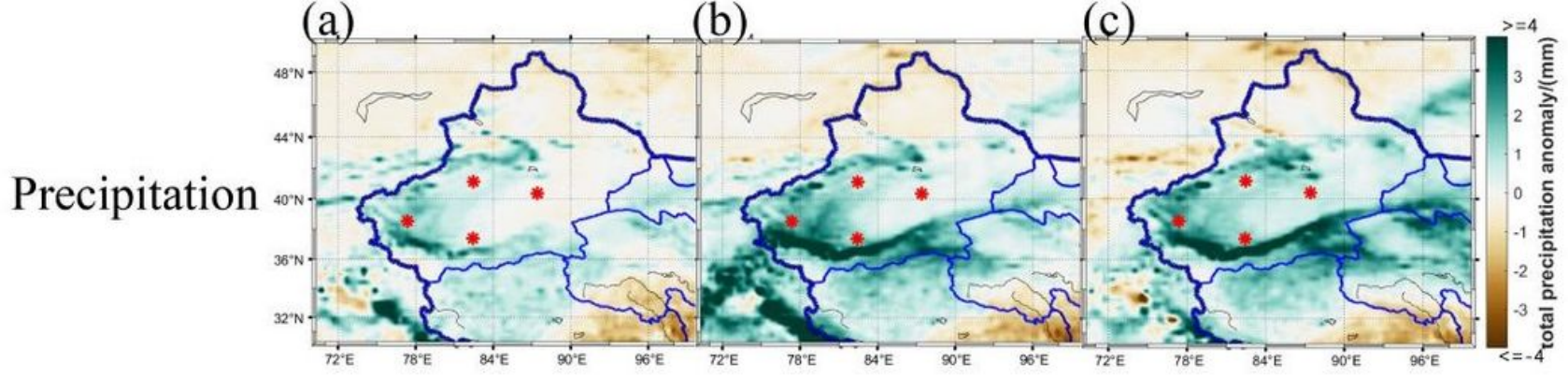

$\mathrm{T} 2 \mathrm{~m}$

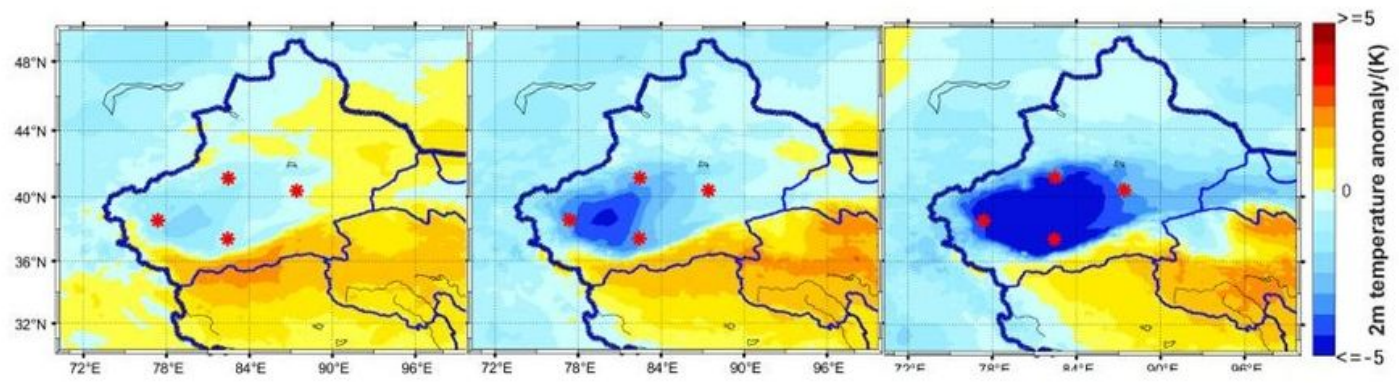

$\mathrm{Z} 500$

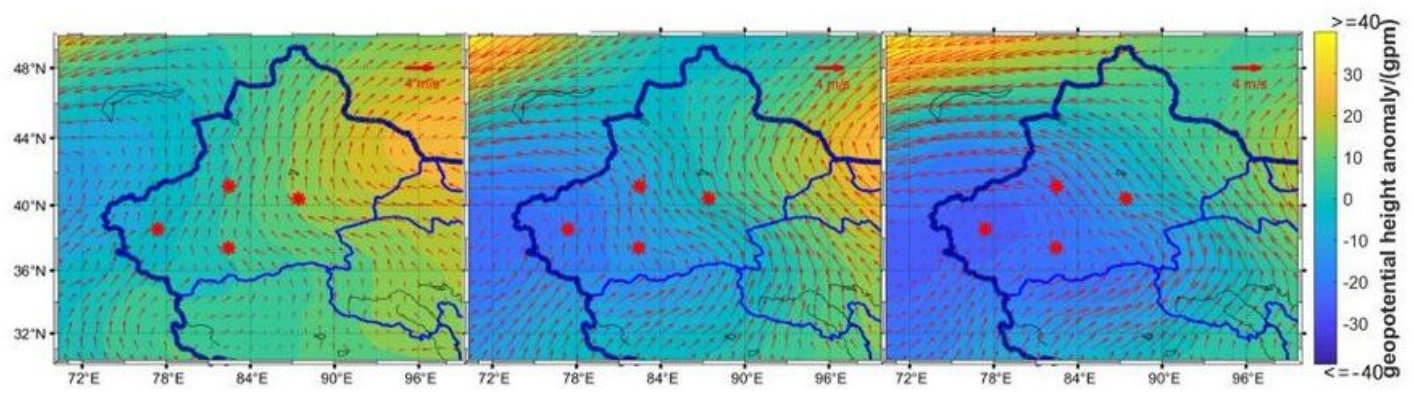

Z850

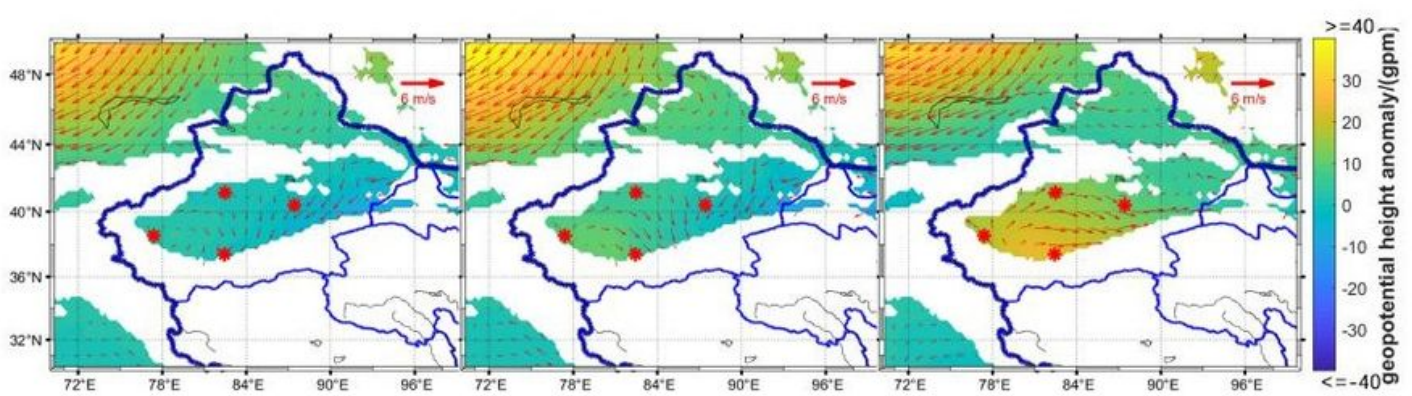

\section{Figure 8}

Please see the Manuscript PDF file for the complete figure caption Note: The designations employed and the presentation of the material on this map do not imply the expression of any opinion whatsoever on the part of Research Square concerning the legal status of any country, territory, city or area or of its authorities, or concerning the delimitation of its frontiers or boundaries. This map has been provided by the authors. 


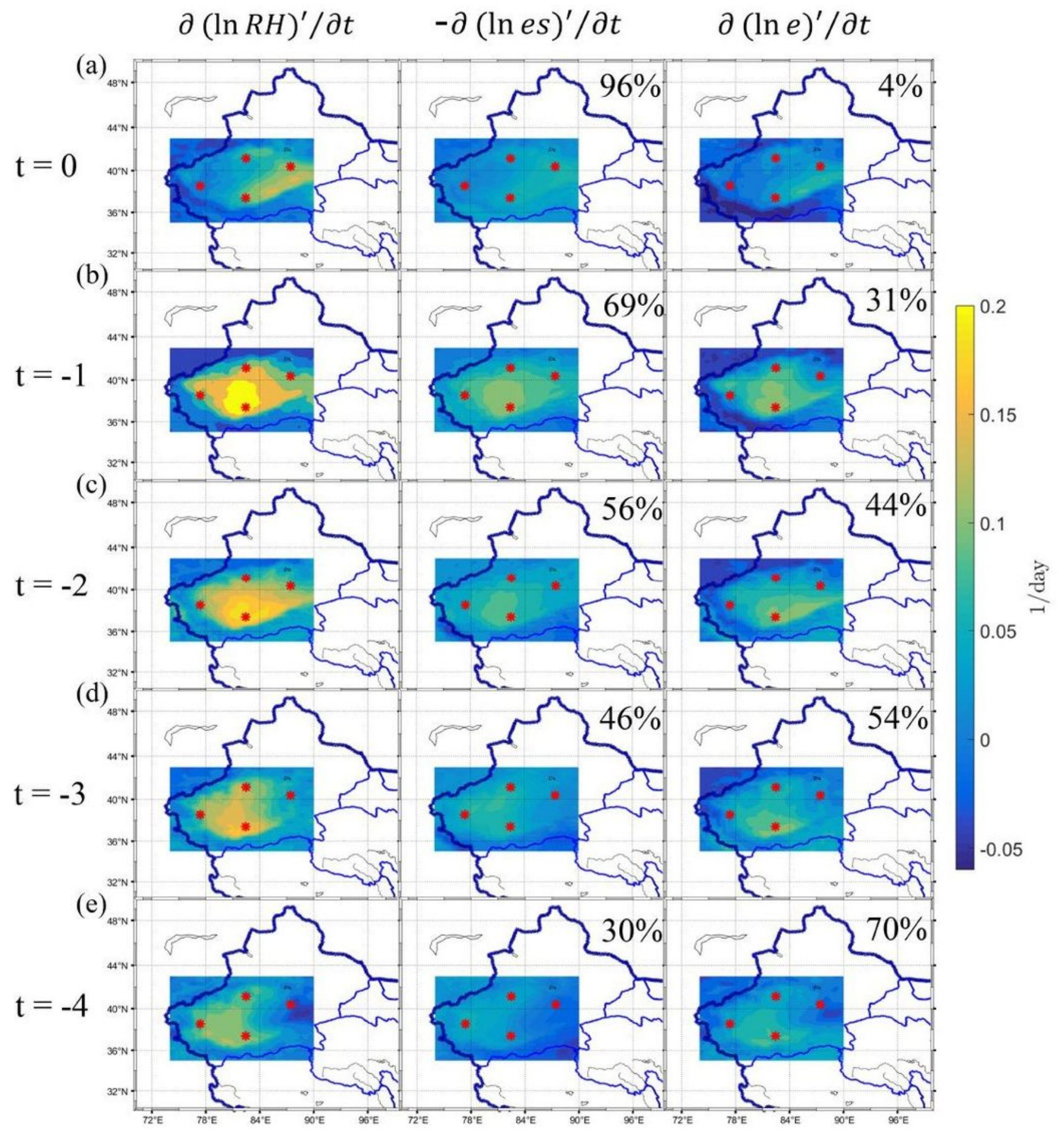

Figure 9

Please see the Manuscript PDF file for the complete figure caption Note: The designations employed and the presentation of the material on this map do not imply the expression of any opinion whatsoever on the part of Research Square concerning the legal status of any country, territory, city or area or of its authorities, or concerning the delimitation of its frontiers or boundaries. This map has been provided by the authors. 


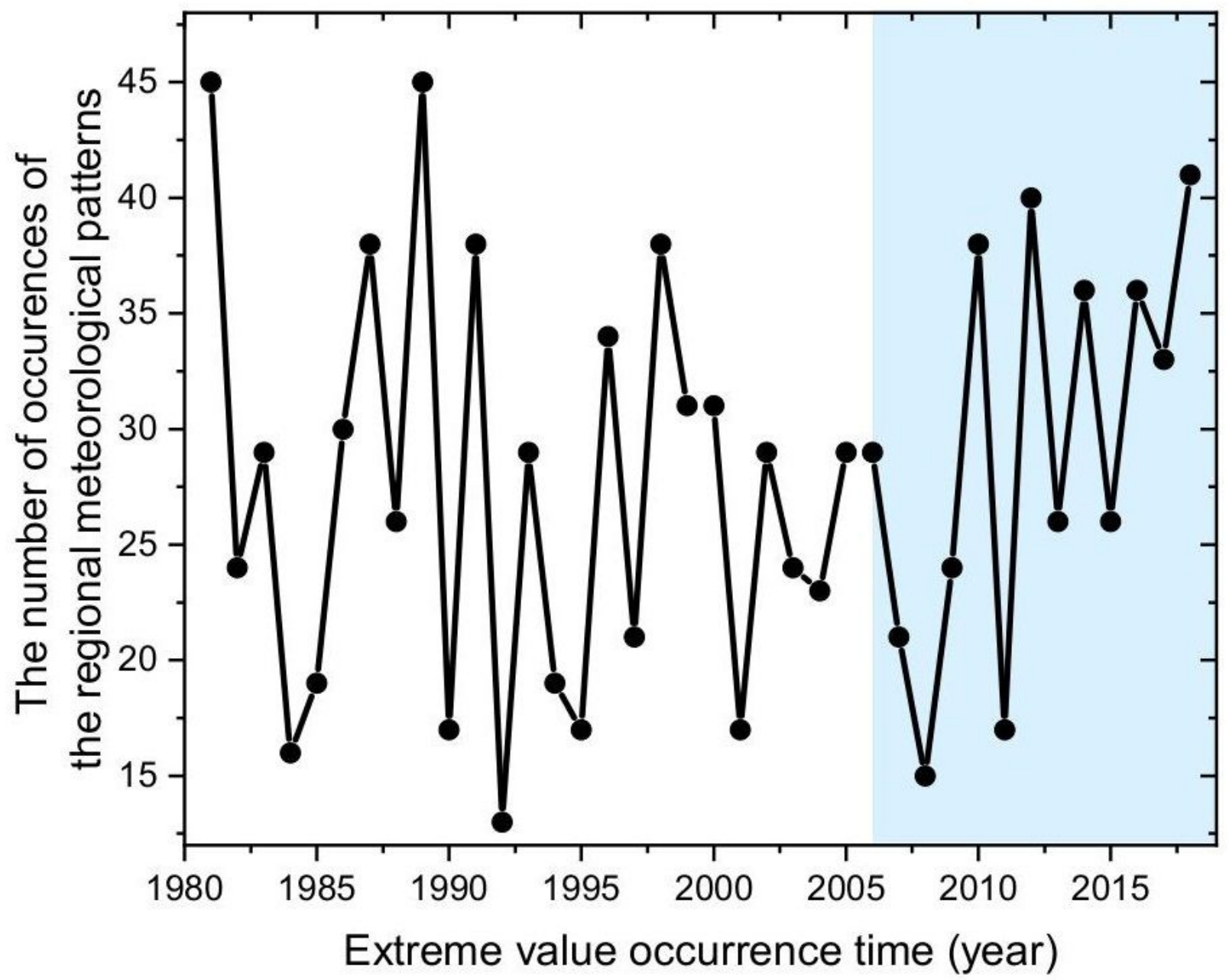

Figure 10

Please see the Manuscript PDF file for the complete figure caption 